\title{
Transcriptomic and metabolomic profiling of ionic liquid stimuli unveils enhanced secondary metabolism in Aspergillus nidulans
}

Paula C. Alves ${ }^{1 \dagger}$, Diego O. Hartmann ${ }^{1 \dagger}$, Oscar Núñez ${ }^{2,3}$, Isabel Martins ${ }^{1}$, Teresa L. Gomes ${ }^{4}$, Helga Garcia ${ }^{1}$, Maria Teresa Galceran², Richard Hampson ${ }^{4}$, Jörg D. Becker ${ }^{5}$ and Cristina Silva Pereira ${ }^{{ }^{*}}$

\begin{abstract}
Background: The inherent potential of filamentous fungi, especially of Ascomycota, for producing diverse bioactive metabolites remains largely silent under standard laboratory culture conditions. Innumerable strategies have been described to trigger their production, one of the simplest being manipulation of the growth media composition. Supplementing media with ionic liquids surprisingly enhanced the diversity of extracellular metabolites generated by penicillia. This finding led us to evaluate the impact of ionic liquids' stimuli on the fungal metabolism in Aspergillus nidulans and how it reflects on the biosynthesis of secondary metabolites (SMs).

Results: Whole transcriptional profiling showed that exposure to $0.7 \mathrm{M}$ cholinium chloride or 1-ethyl-3methylimidazolium chloride dramatically affected expression of genes encoding both primary and secondary metabolism. Both ionic liquids apparently induced stress responses and detoxification mechanisms but response profiles to each stimulus were unique. Primary metabolism was up-regulated by choline, but down-regulated by 1 ethyl-3-methylimidazolium chloride; both stimulated production of acetyl-CoA (key precursor to numerous SMs) and non proteinogenic amino acids (building blocks of bioactive classes of SMs). In total, twenty one of the sixty six described backbone genes underwent up-regulation. Accordingly, differential analysis of the fungal metabolome showed that supplementing growth media with ionic liquids resulted in ca. 40 differentially accumulated ion masses compared to control conditions. In particular, it stimulated production of monodictyphenone and orsellinic acid, otherwise cryptic. Expression levels of genes encoding corresponding polyketide biosynthetic enzymes (i.e. backbone genes) increased compared to control conditions. The corresponding metabolite extracts showed increased cell polarity modulation potential in an ex vivo whole tissue assay (Thelial Live Targeted Epithelia; theLiTETM).
\end{abstract}

Conclusions: Ionic liquids, a diverse class of chemicals composed solely of ions, can provide an unexpected means to further resolve the diversity of natural compounds, guiding discovery of fungal metabolites with clinical potential.

Keywords: Aspergillus nidulans, Monodictyphenone, Orsellinic acid, Secondary metabolism, lonic liquids, Metabolomics, Transcriptomics

\footnotetext{
* Correspondence: spereira@itqb.unl.pt

${ }^{\dagger}$ Equal contributors

${ }^{1}$ Instituto de Tecnologia Química e Biológica António Xavier, Universidade

Nova de Lisboa, Av. da República, 2780-157 Oeiras, Portugal

Full list of author information is available at the end of the article
}

\section{Biomed Central}

(c) 2016 Alves et al. Open Access This article is distributed under the terms of the Creative Commons Attribution 4.0 International License (http://creativecommons.org/licenses/by/4.0/), which permits unrestricted use, distribution, and reproduction in any medium, provided you give appropriate credit to the original author(s) and the source, provide a link to the Creative Commons license, and indicate if changes were made. The Creative Commons Public Domain Dedication waiver (http://creativecommons.org/publicdomain/zero/1.0/) applies to the data made available in this article, unless otherwise stated. 


\section{Background}

Multiple and diverse fungal secondary metabolites (SMs) are already in clinical usage, e.g. the antibiotic penicillin and the antitumor terrequinone A [1]. The inherent SM biosynthetic capacity of fungi remains largely unseen because the majority of these pathways are largely silent (cryptic) under culture conditions used in the laboratory [2]. The presence of various SM backbone genes (encoding non-ribosomal peptide synthases, polyketide synthases, hybrid enzymes, prenyltransferases or terpene cyclases) in fungal genomes hints at the presence of an array of uncharacterised SMs. For example, model fungal species Aspergillus nidulans has sixty six predicted backbone genes [3]; approximately one third of these clusters have been linked to the full range of produced SMs, including monodictyphenone and prenyl xanthones $[4,5]$, asperfuranone [6], emericellamides [7], aspyridone A/B [8], asperthecin [9], terrequinone A $[1,10]$, aspernidine A [11], sterigmatocystin [12], penicillin [13], nidulanin A [14], microperfuranone [15], cichorine [16], orsellinic acid and F9775 A/B [17], austinol and dehydroaustinol [18] and aspercryptin [19].

Closing the gap between genetic potential and the observed diversity of fungal SMs produced constitutes a major challenge [20], further complicated by low production titers and the need for specific stimuli to trigger synthesis [21]. Several strategies have been described to stimulate production of particular SMs; some require prior knowledge of genomic sequences, relying on manipulation of targeted genes encoding components of either secondary metabolism [22] (e.g. aspoquinolones AD [23]) or regulatory pathways (e.g. monodictyphenone [24] and asperthecin [9]). Other approaches may be applied also in less well characterised strains, such as cocultivation methods (e.g. culturing together Emericella spp. and Salinispora arenicola triggers production of two cyclic depsipeptides [25]) or modification of the growth media composition (e.g. addition of sodium citrate or suberoylanilide hydroxamic acid increased the production of terrein in A. terreus [26] and nygerone A in $A$. niger, respectively [27]). We have surprisingly observed that supplementation of growth media with ionic liquids can significantly increase diversity of compounds in the metabolic footprint of penicillia [28]. Ionic liquids comprise a diverse class of chemicals, composed solely by ions and are commonly classified as alternative green solvents (despite many having pronounced toxic effects) [29]. They are also referred to as task-designed solvents, because their properties can be tuned through simple modification of the structure of either ion [30]. More than $10^{9}$ different formulations are theoretically possible, with thousands already available commercially. Recently we analysed the major cellular responses of $A$. nidulans to either cholinium chloride or 1-ethyl-3-methylimidazolium chloride exposure [31]. Selected chemical stimuli are representative of the most studied families of ionic liquids and represent opposite ends of the spectrum regarding toxicity and recalcitrance. Both compounds increase numerous mycelial stress-responsive proteins (e.g. drug transporter proteins) and induce particular developmental changes and production of certain osmolytes [31]. Extracellular compound diversity was apparently greater in $A$. nidulans grown in media supplemented with either ionic liquid than in control cultures. In summary the possibility of ionic liquids being able to activate cryptic SM biosynthetic pathways in fungi deserves further investigation. Here we analyse how cholinium chloride and 1-ethyl-3methylimidazolium chloride impact on both primary and secondary metabolism in A. nidulans. Differential analyses of the fungal metabolome were combined with targeted gene expression analysis and transcriptional profiling (custom Affymetrix microarray [32]). Data highlight ionic liquid's capacity to impact both on primary and secondary metabolism, stimulating SM biosynthesis (e.g. the cryptic SM monodictyphenone). The diversity of differentially formed metabolites apparently comprised also unknown compounds with cell polarity modulation potential (the$\left.\operatorname{LiTE}^{\mathrm{mt}}\right)$. This study sheds first light on the vast potential of ionic liquids to reveal the diversity of natural compound biosynthesis potential in fungi.

\section{Methods \\ Chemicals}

All standard chemicals (toluhydroquinone, orcinol, epoxysuccinic acid, phenoxyacetic acid, 2,5-dihydroxybenzoic acid (gentisic acid), fusaric acid, 3-(3,4-dihydroxyphenyl)-2-propenoic acid (caffeic acid), propyl-3,4,5trihydroxybenzoate, jasmonic acid, sterigmatocystin, penicillin G, physcion and riboflavin) and chromatographic solvents were of highest analytical grade and purchased from either Sigma Aldrich or Fisher Scientific, except ethyl acetate (Acros Organics), orsellinic acid (Alfa Aesar) and chrysophanol (Acros Organics). Water was obtained from a Milli-Q system (Millipore). Cholinium chloride ( $>98 \%$, Sigma Aldrich), hereafter referred to solely as choline, and 1-ethyl-3-methylimidazolium chloride $\left(\left[\mathrm{C}_{2} \mathrm{mim}\right] \mathrm{Cl},>98 \%\right.$, Iolitec $)$ were dried in vacuo $\left(40-70{ }^{\circ} \mathrm{C}, 24-48 \mathrm{~h}, \mathrm{ca} .0 .01 \mathrm{mbar}\right)$ prior to use. Monodictyphenone was kindly provided by Prof. Thomas J. Simpson (University of Bristol, UK) [33].

\section{Fungal strain}

Aspergillus nidulans strain FGSC A4 was cultivated on dichloran-glycerol (DG18) agar (Oxoid), and suspensions of fungal conidia, prepared as previously described [31], were stored at $-80{ }^{\circ} \mathrm{C}$ in cryoprotective solution containing $0.85 \% \mathrm{w} / \mathrm{v} \mathrm{NaCl}$ and $10 \% \mathrm{v} / \mathrm{v}$ glycerol. 


\section{Culture condition}

Fungal cultures $(5 \mathrm{~mL}$ or $50 \mathrm{~mL})$ were initiated from conidia $\left(10^{5}\right.$ conidia per $\left.\mathrm{mL}\right)$ in a $0.1 \%$ glucose mineral growth media [31] alone (control) or containing $0.7 \mathrm{M}$ $\left[\mathrm{C}_{2} \mathrm{mim}\right] \mathrm{Cl}$ or choline (dosage equivalent to $50 \%$ of the minimal inhibitory concentration of $\left.\left[\mathrm{C}_{2} \mathrm{mim}\right] \mathrm{Cl}[31]\right)$. Liquid cultures (triplicates) were incubated in the dark at $27{ }^{\circ} \mathrm{C}$ with orbital agitation (90 rpm), for defined periods of time (2, 5, 7, 10 or 15 days). At the end of incubation, fungal mycelia (mostly submerged) were recovered by filtration (glass fibre pre-filters) and both mycelia and filtrate were immediately frozen in liquid nitrogen and stored at $-80{ }^{\circ} \mathrm{C}$, until further analysis.

\section{Microscopic analysis}

Mycelia were recovered from fungal cultures after fifteen days of incubation $(50 \mathrm{~mL}$; inoculated and incubated as described above, triplicate samples), mounted on glass slides and stained with lactophenol blue to enhance contrast. Visualisation of cultures was performed using a DM5500 B microscope (Leica) with $40 \times$ or $63 \times$ magnification objectives and images were captured with a DFC420 C camera (Leica).

\section{RNA isolation and CDNA synthesis}

Total RNA was isolated from mycelia (previously ground to a powder using mortar and pestle in liquid nitrogen) using the RNeasy Plant Mini Kit (QIAGEN) and further purified following standard ethanol precipitation. Quantity and quality of RNA was determined using a NanoDrop 1000 Spectrophotometer (Thermo Scientific) and RNA integrity assessed by using an Agilent 2100 Bioanalyser with a RNA 6000 Nano Assay (Agilent Technologies). cRNA was fragmented and biotinylated according to GeneChip 3' IVT Express Kit protocols. Briefly, $100 \mathrm{ng}$ total RNA were used for cDNA synthesis, which was in vitro transcribed to generate labelled cRNA. After purification and fragmentation, the size distribution of cRNA and fragmented cRNA was assessed using an Agilent 2100 Bioanalyzer with an RNA 6000 Nano Assay.

\section{DNA microarray processing}

The custom DNA microarray FungiANC (Affymetrix) was used in this study [32]. The chip contains a total of 20,012 transcripts derived from the genetic information of A. nidulans and Neurospora crassa (Broad Institute Database, www.broadinstitute.org) and is based on a Perfect Match-only design with $11 \mu \mathrm{m}$ feature size. Each transcript is represented by 11 oligonucleotides of 25 mer (detailed description in Additional file 1). The array was processed following Affymetrix GeneChip protocols, in biological triplicates. A total of $200 \mu \mathrm{l}$ hybridization mixture containing $10 \mu \mathrm{g}$ fragmented cRNA was hybridized to arrays for $16 \mathrm{~h}$ at $45{ }^{\circ} \mathrm{C}$. Standard post- hybridization washes and double-stain protocols (FS450_0001) were used on an Affymetrix GeneChip Fluidics Station 450, in conjunction with the GeneChip Hybridization Wash and Stain Kit (Affymetrix). Arrays were scanned on an Affymetrix GeneChip Scanner 3000 7G. All array quality parameters were analysed by Expression Console Software (Affymetrix) for Robust Multiarray Averaging (summarised data) and confirmed to be in the recommended range. The data herein presented have been deposited in NCBI's Gene Expression Omnibus [34] and are accessible through GEO Series accession number GSE65946 (www.ncbi.nlm.nih.gov/ geo/query/acc.cgi?acc=GSE65946).

\section{Microarray data analysis}

Microarray data analysis was performed using DNAChip Analyzer (dChip) software (www.dchip.org, 2010), applying a probeset mask file considering only $A$. nidulans probes (9674 transcripts). Arrays were normalised to a baseline array with median CEL intensity by applying an Invariant Set Normalization Method [35, 36]. Normalised CEL intensities of the 9 arrays were used to obtain model-based gene expression indices based on a Perfect Match-only model $[35,36]$. Log2 expression data produced by dChip was imported into R v2.13.0 and differential gene expression analysed with the Bioconductor LIMMA package (www.bioconductor.org) [37]. Principal component analysis and volcano plots were obtained to validate biological replicates and visualise distribution of statistically significant data from each biological condition (Additional file 1). Differentially expressed genes (adjusted $p$-value $\leq 0.05, \quad|\mathrm{FC}| \geq 1.5$ ), identified using pair-wise comparison between each condition and control (grown on glucose) (Additional file 2), were analysed with Venn diagrams (Venny, http://bioinfogp.cnb.csic.es/ tools/venny/index.html) (Additional file 1).

\section{Functional annotation}

Annotation of all genes represented on the DNA microarray was obtained from the Broad Institute Database and the Aspergillus Genome Database (www.aspgd.org). Full details are given in Additional file 2. Differentially expressed genes for each condition were classified using the FungiFun web annotation tool (https://sbi.hkijena.de/FungiFun) [38]. Significant hits $(p$-value $\leq 0.05)$ were defined using the identities present on the chip as background (Additional file 1).

\section{Quantitative real-time PCR}

All quantitative real-time PCR (qRT-PCR) oligonucleotide pairs - based on A. nidulans gene sequences (Aspergillus Genome Database, www.aspgd.org) - were designed using the GeneFisher2 web tool (http://bibiserv.techfak.uni-bielefeld.de/genefisher2) and produced 
by Thermo Fisher Scientific (Additional file 1). qRT-PCR analyses were performed in a CFX96 Thermal Cycler (Bio-Rad), using the SsoFast EvaGreen Supermix (BioRad), $250 \mathrm{nM}$ of each oligonucleotide and cDNA template equivalent to $1 \mathrm{ng}$ total RNA, in a final volume of $10 \mu \mathrm{l}$ per well (three technical and three biological replicates). PCR conditions were: enzyme activation at $95{ }^{\circ} \mathrm{C}$ for $30 \mathrm{~s} ; 40$ cycles of denaturation at $95{ }^{\circ} \mathrm{C}$ for $10 \mathrm{~s}$ and annealing/extension at $59{ }^{\circ} \mathrm{C}$ for $30 \mathrm{~s}$; and melting curve obtained from $65{ }^{\circ} \mathrm{C}$ to $95{ }^{\circ} \mathrm{C}$, consisting of $0.5^{\circ} \mathrm{C}$ increments every $5 \mathrm{~s}$. Data analysis was performed using the CFX Manager Software v3.0 (Bio-Rad). Expression of each gene was calculated relative to control. Expression of all target genes was normalised to the expression of the histone H3 gene, used as internal control.

\section{Metabolite extraction and analyses}

Lyophilised culture filtrates were homogenised in Milli$\mathrm{Q}$ water and extracted three times with ethyl acetate (1:1), dried under soft nitrogen flow and resuspended in a minimal volume of methanol. Preliminary mass spectrometry analyses of the extracts showed much higher abundance of differential $\mathrm{m} / \mathrm{z}$ in negative mode compared to positive mode (data now shown). For that reason, ultra-high performance liquid chromatographyelectrospray ionisation-high resolution mass spectrometry (UHPLC-ESI-HRMS) analyses of metabolite extracts were performed in negative mode using a Q-Exactive Orbitrap MS system (ThermoFisher Scientific) equipped with a heated electrospray ionisation source (HESI-II) [39]. Chromatographic separation was carried out in an UHPLC system (Accela; ThermoFisher Scientific) using an Ascentix Express C18 $(150 \times 2.1 \mathrm{~mm}, 2.7 \mu \mathrm{m}$ particle size) column from Supelco (USA). The mobile phase, at a flow rate of $300 \mu \mathrm{L} / \mathrm{min}$, consisted of a solution of $0.1 \%$ formic acid (solvent A) and a solution of acetonitrile containing $0.1 \%$ formic acid (solvent B), set as follows: $10 \% \mathrm{~B}$ in $1 \mathrm{~min}$, followed by a liner gradient of $10-95 \% \mathrm{~B}$ in $4.7 \mathrm{~min}, 1.3 \mathrm{~min}$ to reach $100 \% \mathrm{~B}, 3 \mathrm{~min}$ of $100 \% \mathrm{~B}, 0.5 \mathrm{~min}$ to return to the initial conditions, and $5.5 \mathrm{~min}$ to re-equilibrate the column. HESI-II was operated in negative ionisation mode. Nitrogen was used as a sheath gas, sweep gas and auxiliary gas at flow rates of 60, 0 and 10 a.u. (arbitrary units), respectively. Heater temperature was set at $350{ }^{\circ} \mathrm{C}$. Capillary temperature was set at $320^{\circ} \mathrm{C}$ and electrospray voltage at $-2.5 \mathrm{kV}$. A S-Lens RF level of $50 \mathrm{~V}$ was used. Q-Exactive Orbitrap MS system was tuned and calibrated using ThermoFisher calibration solution once a week. The HRMS instrument was operated in full MS scan with a $m / z$ range from 50 to 600 , and the mass resolution tuned into 70,000 full width half maximum (FWHM) at $\mathrm{m} / z$ 200, with an automatic gain control (AGC) target (the number of ions to fill C-Trap) of 5.0E5 with a maximum injection time (IT) of $200 \mathrm{~ms}$. The full MS scan was followed by a data-dependent scan operated in All Ion Fragmentation (AIF) mode with a fragmentation energy applied of $30 \mathrm{eV}$ into the high-energy collision dissociation (HCD) cell. At this stage, mass resolution was set at $17,500 \mathrm{FWHM}$ at $\mathrm{m} / z 200$, AGC target at 5.0E5, maximum IT at $200 \mathrm{~ms}$, and the scan range also from $\mathrm{m} / \mathrm{z}$ 50 to 600 . MS data were processed by ExactFinder ${ }^{\text {rat }}$ v2.0 software (Thermo Fisher) by applying a user target database list, comprising nearly one thousand four hundred SMs previously described in Ascomycota (Additional file 3). Parameters including retention time, accurate mass errors and isotopic pattern matches were used in preliminary manual compound identification. Analytical standards of monodictyphenone, chrysophanol, orsellinic acid, toluhydroquinone, orcinol, epoxysuccinic acid, phenoxyacetic acid, 2,5-dihydroxybenzoic acid (gentisic acid), fusaric acid, 3-(3,4-dihydroxyphenyl)-2-propenoic acid (caffeic acid), propyl-3,4,5-trihydroxybenzoate, jasmonic acid, sterigmatocystin, physcion and riboflavin were used for compound identity validation, applying following criteria: $\Delta R T \leq 0.2 \mathrm{~min}$ and $\Delta(\mathrm{m} / \mathrm{z}) \leq 5 \mathrm{ppm}$. Mycelial accumulation of betaine was quantified as previously reported [31].

\section{Ex vivo assay for anti-carcinoma activity}

Cell polarity is central to onset and progression of diseases including carcinoma; validated assay theLiTE measures polarity modulating activity of compounds in live Drosophila tissues. All tests were conducted as disclosed in published US patent application 20130136694. Briefly, egg chambers are extracted from female Drosophila less than 7 days old and exposed to metabolites (pure compounds and both the crude metabolite extracts and their polar fractions [40]) at standardised concentrations in Schneider's culture medium under controlled standard atmospheric conditions for up to $6 \mathrm{~h}$. Egg chambers are observed using standard light and fluorescence microscopy and scored for presence/absence of polarity marker protein Par6. Each assay is done in triplicate. Controls for these assays included pure compounds: the-103 (a functional equivalent of aurothiomalate [41], which displays $100 \%$ activity in the$\mathrm{LiTE}^{\mathrm{sm}}$ ), monodictyphenone, orsellinic acid and either ionic liquid, as well as the blank (0.6 \% v/v DMSO) and metabolite extracts of the control cultures and the noninoculated media.

\section{Results and discussion}

\section{Aspergillus nidulans differential metabolic footprints under ionic liquid stimuli}

The diversity of compounds in the metabolic footprint of fungi depends on growth media composition (e.g. carbon and nitrogen sources availability) [42]. Simple, 
systematic compositional alterations allow discovery of multiple SMs in a single producing organism [43]. This strategy, usually known as the "one strain-many compounds approach", provides high flexibility for screening poorly characterised strains. Adding sub-lethal concentrations of an ionic liquid to the growth media of Penicillium spp. [28] or A. nidulans [31] augmented the diversity of compounds in the culture footprints. High resolution spectrometric analyses of $A$. nidulans metabolite extracts were performed to expand our initial findings. Compared to control conditions ionic liquid stimuli altered the fungal metabolic footprint, increasing the diversity of metabolites (Fig. 1). By applying a user target list of Ascomycota SMs, a list of differential ion masses $(\mathrm{m} / \mathrm{z})$ detected under an ionic liquid stimulus, when compared to the control, could be produced (Additional file 3). There were $c a$. 40 differential ion masses detected in either ionic liquid medium when compared to the control, with 24 and 18 specific to choline or 1-ethyl-3-methylimidazolium chloride supplemented media, respectively (Additional file 3).

Most ion masses matched compounds present in our user target list but only six compound identifications could be validated with standards (Table 1). These included four known metabolites of Aspergillus: orcinol [44, 45], phenoxyacetic acid [46], orsellinic acid [17] and monodictyphenone [24], as well as gentisic acid and caffeic acid which, to the best of our knowledge, are reported here for the first time in A. nidulans. Gentisic acid has previously been detected in Penicillium griseofulvum [47], whereas caffeic acid was reported only once in a fungal metabolite screening [48]. None of the remaining putative identifications could be validated with the corresponding standards, e.g. chrysophanol and

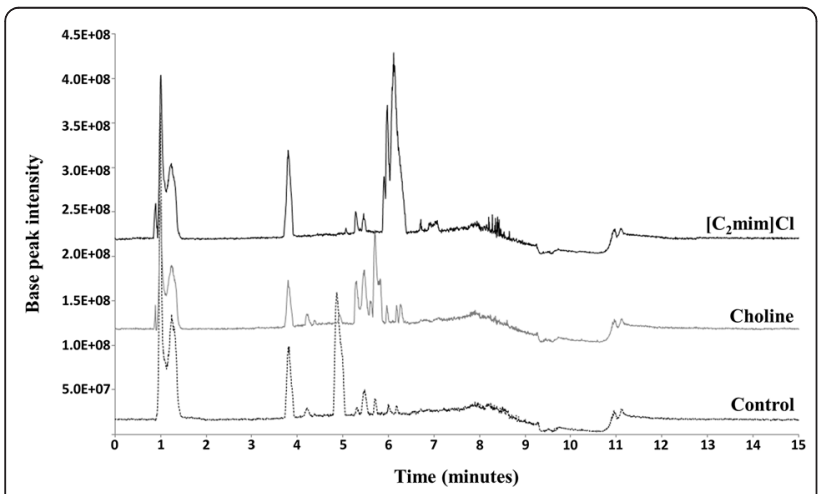

Fig. 1 Chromatographic analyses of the metabolic footprint of Aspergillus nidulans under ionic liquid stimuli. The base peak intensity chromatograms of the culture extracts after fifteen days of incubation in either choline or 1-ethyl-3-methylimidazolium chloride ([ $\left.\left.\mathrm{C}_{2} \mathrm{mim}\right] \mathrm{Cl}\right)$ supplemented media revealed higher diversity of metabolites when compared to the control sterigmatocystin. None of the ion masses identified here matched penicillin, confirming its absence.

Among identified compounds we found two already characterised cryptic SMs (Table 1). Monodictyphenone, exclusively found in choline supplemented media, and orsellinic acid, found with both ionic liquid supplements (Fig. 2). Monodictyphenone is a product of the monodictyphenone biosynthetic pathway in A. nidulans [4, 5, 24, 33], initially characterised in a $\triangle c c l A$ strain $(n . b . c c l A$ encodes a methyltransferase known to impact secondary metabolism) [24]. Orsellinic acid has been detected in A. nidulans during co-cultivation with Streptomyces hygroscopicus [49] and, more recently, also in sucrose supplemented media [17]. The production of the otherwise cryptic derivatives of the monodictyphenone cluster (e.g. emodin and chrysophanol), and orsellinic acid, was stimulated in $A$. nidulans grown in continuous fermentation under nutrient limited conditions [50].

\section{Transcriptome profiling of $A$. nidulans during exposure to ionic liquids}

To shed light on the impact of ionic liquids on the $A$. nidulans transcriptome, including genes encoding components involved in secondary metabolism - either biosynthesis or regulation - whole-genome profiling analysis (FungiANC) [32] was performed. Raw signal intensities for all genes are given in Additional file 2. Principal Component Analysis showed that the biological replicates of each condition were clustered together (implying a very low degree of replicate variation in transcript levels) and dissociated from the remaining clusters (Additional file 1). Volcano plots clearly show a great number of transcripts with highly significant differential expression (Additional file 1). Pair-wise comparison was used to identify genes expressed differentially between the control and cultures grown in ionic liquid media for fifteen days (adjusted $p$-value $\leq 0.05$ and $|\mathrm{FC}| \geq$ 1.5). In either ionic liquid media $c a .35 \%$ of transcripts (total of 9674) showed altered expression levels, but only ca. $6 \%$ were altered by both (Venn diagrams in Additional file 1). Choline supplementation led to up- and downregulation of 1252 and 811 transcripts, respectively. 1Ethyl-3-methylimidazolium chloride supplement, upregulated 1207 transcripts and down-regulated 1271 transcripts. According to the functional categories database of the Munich Information Center for Protein Sequences (MIPS), the differentially expressed genes were enriched in the categories metabolism (MIPS 01), energy (MIPS 02), transcription (MIPS 11) and protein synthesis (MIPS 12). In general, most of these functional categories were upregulated in choline medium but down-regulated in 1ethyl-3-methylimidazolium chloride medium (Additional file 1). These findings match those of our previous proteomic profiling study [31], which reflect the distinct biodegradability and toxicity of these ionic liquids. 
Table 1 Metabolites differentially produced under ionic liquid stimuli

\begin{tabular}{|c|c|c|c|c|c|}
\hline$m / z$ & Choline & {$\left[\mathrm{C}_{2} \mathrm{mim}\right] \mathrm{Cl}$} & Molecular formula & Compound identification & Reference \\
\hline 123.0450 & $\mathrm{a}$ & $\checkmark$ & $\mathrm{C} 7 \mathrm{H} 8 \mathrm{O} 2$ & orcinol & {$[34,35]$} \\
\hline 151.0402 & & $\checkmark$ & $\mathrm{C} 8 \mathrm{H} 8 \mathrm{O} 3$ & phenoxyacetic acid & [36] \\
\hline 153.0195 & $\checkmark$ & & $\mathrm{C} 7 \mathrm{H} 6 \mathrm{O} 4$ & 2,5-dihydroxybenzoic acid (gentisic acid) & {$[38,39]$} \\
\hline 167.0348 & $\checkmark^{b, c}$ & $\checkmark^{b, c}$ & $\mathrm{C} 8 \mathrm{H} 8 \mathrm{O} 4$ & orsellinic acid & {$[37,39]$} \\
\hline 179.0352 & $\checkmark$ & $\checkmark$ & $\mathrm{C} 9 \mathrm{H} 8 \mathrm{O} 4$ & 3-(3,4-dihydroxyphenyl)-2-propenoic acid (caffeic acid) & [39] \\
\hline 287.0566 & $\boldsymbol{\sigma}^{c}$ & & $\mathrm{C} 15 \mathrm{H} 12 \mathrm{O} 6$ & monodictyphenone & [14] \\
\hline
\end{tabular}

UHPLC-ESI-HRMS differential analyses of putative compounds (ion masses) detected in the metabolite extracts of either choline or 1-ethyl-3-methylimidazolium chloride $\left(\left[\mathrm{C}_{2} \mathrm{mim}\right] \mathrm{Cl}\right)$ supplemented media, compared to the control. Compound identifications were validated by the corresponding standards

a a compound reported equal $\mathrm{m} / \mathrm{z}$ value but was not validated as orcinol; ${ }^{\mathrm{b}}$ vestigial amounts also found in the control; ${ }^{\mathrm{C}}$ also detected in early time-points: monodictyphenone was detected after 5 and 10 days of incubation in choline media; and orsellinic acid was detected after 5 days of incubation in choline media and after 10 days of incubation in $\left[\mathrm{C}_{2} \mathrm{mim}\right] \mathrm{Cl}$ media

\section{lonic liquids impact on stress response and primary metabolism of $A$. nidulans}

Filamentous fungi respond to very diverse environmental stresses by activating different signalling transduction cascades [51-54]. Extracellular signals are usually sensed and transmitted to response regulators [55] that also impact other processes, ranging from asexual development and cell wall integrity to fungicide sensitivity [53]. Aspergillus nidulans can tolerate saline concentrations considerably higher than those used here [56]. Both ionic liquids up-regulated the response regulator of the high osmolarity glycerol (HOG) pathway - sskA (AN7697) (Table 2), but none of the downstream elements ( $p b s B$, AN0931; $\operatorname{hog} A, A N 1017 ; s s k B, A N 10153)$ nor any transcription factors regulated by this pathway (e.g. atfA, AN2911 and srrA, AN3688) [57]. In 1-ethyl-3-methylimidazolium chloride supplemented medium, sskA up-regulation occurred together with genes coding for catalase A (catA, AN8637), glycerol-3-phosphate dehydrogenase ( $g f d B, \quad$ AN6792), trehalose-6-phosphate phosphatase (orlA, AN3441), neutral trehalase (treB,
AN5635) and NADP(+)-dependent glycerol dehydrogenase (gldB, AN5563) (Table 2), strongly suggesting the formation of stress-tolerant conidia $[53,58]$. In fact, conidia formation was observed in the floating mycelia at the surface of the liquid media in both cultivation conditions.

It has previously been suggested that 1-ethyl-3-methylimidazolium chloride can induce autolysis in $A$. nidulans [31], a process of self-digestion of aged hyphae [59]. Proteome profiling showed the increase of two autolysis hallmark proteins, $\beta$-1,3-endoglucanase (EngA, AN0472) and chitinase B (ChiB, AN4871), during growth in ionic liquid supplemented media [31]. The corresponding transcripts were not found to be up-regulated here. Upregulation of AN10213 (autophagy protein Apg6) and AN6360 (homolog of ATG17) suggests autophagy was occurring (Table 2). This process is related to nutrient recycling during starvation and has been shown to precede autolysis [60]. Microscopic analysis showed that by incubation day fifteen, mycelia and hyphae of $A$. nidulans grown in choline supplemented medium were more



Fig. 2 Total ion chromatogram (TIC) of Aspergillus nidulans metabolite extracts under ionic liquid stimuli. TIC derived from fifteen day cultures in choline or 1-ethyl-3-methylimidazolium chloride $\left(\left[\mathrm{C}_{2} \mathrm{mim}\right] \mathrm{Cl}\right)$ supplemented media. Extracted ion chromatograms (EIC) and respective HRMS spectra for peaks corresponding to monodictyphenone and orsellinic acid are also presented 
Table 2 Genes of stress response differentially expressed after ionic liquid stimuli

\begin{tabular}{|c|c|c|c|c|}
\hline \multirow[b]{2}{*}{ GenelD } & \multirow[b]{2}{*}{ Gene } & \multicolumn{2}{|c|}{ Transcriptional profile* } & \multirow[b]{2}{*}{ Description } \\
\hline & & Choline & {$\left[\mathrm{C}_{2} \mathrm{mim}\right] \mathrm{Cl}$} & \\
\hline AN7697 & sskA & 1.81 & 1.49 & response regulator \\
\hline AN0931 & pbs $B$ & -1.67 & 1.30 & HOG signaling pathway MAPKK \\
\hline AN1017 & $\operatorname{hog} A$ & -1.73 & 1.01 & osmotic stress-activated kinase \\
\hline AN8637 & catA & -2.32 & 1.94 & catalase A \\
\hline AN9339 & catB & 2.66 & 1.21 & catalase B \\
\hline AN5918 & catC & 2.34 & -4.09 & catalase C \\
\hline AN7388 & cpeA & 2.76 & -2.79 & catalase D, catalase-peroxidase \\
\hline AN5523 & $\operatorname{tps} A$ & -1.85 & 1.37 & trehalose-6-phosphate synthase subunit 1 \\
\hline AN3441 & orlA & -1.74 & 2.62 & trehalose-6-phosphate phosphatase \\
\hline AN5635 & treB & 1.39 & 2.34 & neutral trehalase \\
\hline AN6792 & $g f d B$ & -3.56 & 2.69 & glycerol-3-phosphate dehydrogenase \\
\hline AN5563 & gldB & -1.28 & 2.74 & NADP(+)-dependent glycerol dehydrogenase \\
\hline \multicolumn{5}{|c|}{ Glutathione metabolism } \\
\hline AN2846 & $g p \times A$ & 1.23 & -2.65 & glutathione peroxidase \\
\hline AN4905 & gstA & -2.04 & -1.29 & theta class glutathione S-transferase \\
\hline AN3299 & & 3.58 & 2.11 & glutathione S-transferase \\
\hline AN6158 & & 1.89 & 3.15 & glutathione S-transferase \\
\hline AN10444 & ggtA & 2.30 & 1.48 & gamma-glutamyltranspeptidase \\
\hline AN5658 & & 2.58 & -1.93 & gamma-glutamyltranspeptidase \\
\hline AN3459 & & 1.98 & -2.09 & glutamate carboxypeptidase \\
\hline AN2514 & & -1.16 & 2.81 & gamma-cysteine synthetase regulatory subunit \\
\hline \multicolumn{5}{|c|}{ Multidrug transporters } \\
\hline AN0015 & & 2.01 & 1.68 & ABC multidrug transporter \\
\hline AN2349 & & -4.55 & 1.02 & $\mathrm{ABC}$ multidrug transporter \\
\hline AN6443 & & 2.14 & -1.28 & ABC multidrug transporter \\
\hline AN8150 & & 1.48 & 3.80 & $\mathrm{ABC}$ multidrug transporter \\
\hline AN8489 & & 7.89 & -1.64 & ABC multidrug transporter \\
\hline AN8892 & & 2.10 & 73.69 & ABC multidrug transporter \\
\hline AN9342 & & 2.11 & 2.60 & ABC multidrug transporter \\
\hline AN0732 & & 4.78 & 2.94 & MFS multidrug transporter \\
\hline AN1243 & & 1.03 & 2.17 & MFS multidrug transporter \\
\hline AN1691 & & 1.04 & 2.19 & MFS multidrug transporter \\
\hline AN2531 & & -3.69 & 2.22 & MFS multidrug transporter \\
\hline AN3301 & & 1.36 & 7.78 & MFS multidrug transporter \\
\hline AN6477 & & 6.42 & 1.48 & MFS multidrug transporter \\
\hline AN6942 & & 8.86 & 77.17 & MFS multidrug transporter \\
\hline AN7295 & & 3.12 & 1.25 & MFS multidrug transporter \\
\hline AN7466 & & 1.62 & 2.52 & MFS multidrug transporter \\
\hline AN8089 & & 3.70 & -1.47 & MFS multidrug transporter \\
\hline AN8610 & & 3.04 & 1.05 & MFS multidrug transporter \\
\hline AN8621 & & -5.58 & 2.92 & MFS multidrug transporter \\
\hline \multicolumn{5}{|c|}{ Autolysis/autophagy } \\
\hline AN0472 & engA & -3.46 & -3.39 & $\beta$-1,3-endoglucanase \\
\hline
\end{tabular}


Table 2 Genes of stress response differentially expressed after ionic liquid stimuli (Continued)

\begin{tabular}{|c|c|c|c|c|}
\hline AN4871 & chiB & -2.41 & -5.07 & chitinase B \\
\hline AN1760 & & -1.81 & 1.28 & autophagy protein Apg12 \\
\hline AN3734 & & -1.69 & -1.26 & autophagy protein Apg9 \\
\hline AN5876 & & -1.94 & -1.30 & autophagy protein Atg22 \\
\hline AN6360 & & 1.01 & 1.50 & autophagy protein, ATG17 homolog \\
\hline AN10213 & & 2.00 & 4.30 & autophagy protein Apg6 \\
\hline
\end{tabular}

Microarray analyses (fold-change, $\mathrm{FC}$ ) in choline or 1-ethyl-3-methylimidazolium chloride ([C2mim]Cl) supplemented media in pair-wise comparisons with the control. Values highlighted in bold are statistically significant $(|\mathrm{FC}| \geq 1.5$ and $p$-value $\leq 0.05)$

*values highlighted in bold have $|\mathrm{FC}| \geq 1.5$ and $p$-value $\leq 0.05$ in the microarray data

robust than those grown in 1-ethyl-3-methylimidazolium chloride supplemented medium, which in turn were similar to the control culture (Fig. 3a). The formation of Hülle cells was detected in the choline medium (Fig. 3b), as also seen in our previous study [31]. This is consistent with the observed up-regulation of the catalase $\mathrm{D}$ gene (cpeA, AN7388) (Table 2), induced in these specialised cells during sexual development [61].

Aspergillus nidulans is able to take up choline as a source of carbon and nitrogen [62]. In choline supplemented medium a great number of genes involved in the central carbon and amino acids metabolisms were upregulated (Fig. 4, Additional file 1), suggesting activation of primary metabolism. Choline can be phosphorylated and incorporated into phosphatidylcholine, a principal constituent of cellular membranes [63]. Excess of phosphatidylcholine is counterbalanced by its degradation into for example 1,2-diacylglycerol, as suggested by the up-regulation of the phospholipase $\mathrm{C}$ gene $(p l c B$, AN7691) (Additional file 2). In our previous proteomic study [31], we observed that choline was most likely taken up and metabolised via the glycine, serine and threonine metabolic pathway, and incorporated into the central carbon metabolism. The transcriptomic data reported here further confirm these observations. Upregulation of betaine aldehyde dehydrogenase (AN1430) and dimethylglycine oxidase (AN8654) supports the hypothesis that choline enters the primary metabolism through formation of betaine aldehyde and betaine, which is further converted to glycine (Fig. 4). The threefold accumulation of betaine in the mycelia under choline supplementation when compared to the control (39.43 \pm $5.29 \mathrm{mg} / \mathrm{mL}$ and $12.25 \pm 6.42 \mathrm{mg} / \mathrm{mL}$, respectively) further supports this hypothesis. Downstream steps indicate the formation of serine from glycine (up-regulation of AN1198, AN1342 and AN10745) and its conversion into pyruvate, as evidenced by the major up-regulation of the serine dehydratase gene (AN3866), which reached almost 119-fold (Additional file 1). As a consequence of this influx of carbohydrates, most genes involved in the tricarboxylic acid (TCA) cycle and glyoxylate shunt were upregulated (Fig. 4). Some genes involved in glycolysis/ gluconeogenesis were also up-regulated (e.g. fructosebisphosphate aldolase, AN2334; triosephosphate isomerase tpiB, AN5908; and glyceraldehyde-3-phosphate dehydrogenase $g p d C$, AN2583), suggesting the incorporation of these carbon sources into other metabolic pathways. For example, the activation of the non-oxidative phase of the pentose phosphate pathway (involved in the biosynthesis of precursors of nucleotides and some amino acids) is supported by the up-regulation of ribose 5-phosphate isomerase (AN5907) and deoxyribose-phosphate aldolase (AN4772). Most metabolic pathways of amino acids were affected by choline supplementation, up-regulating genes involved in the metabolism of cysteine and methionine; aspartate, alanine and asparagine; branched and aromatic amino acids; glutamate, glutamine and proline, among others (Fig. 4, Additional file 1). Excessive supplementation with choline induced accumulation of cyanase [31]; consistent with the up-regulation of the encoding gene (AN7331) observed here (Fig. 4, Table 2). Since cyanide mineralisation is mediated by this enzyme [64], the accumulation of this toxic compound may partially explain how excess choline may result in growth inhibition and activation of stress response in $A$. nidulans.

Major down-regulation on the primary metabolism of A. nidulans was provoked by 1-ethyl-3-methylimidazolium chloride, as previously suggested by our proteomic study [31]. Genes involved in glycolysis and TCA cycle were mostly down-regulated, probably a consequence of nutrient limitation (Fig. 4, Additional file 1). This is also strongly sustained by the down-regulation of the majority of the genes involved in the biosynthesis of amino acids. A few exceptions were observed, such as the upregulation of genes involved in alanine, aspartate and asparagine metabolism, namely asparaginases (ahtA, AN0300; AN1891; and AN9195), asparagine synthetase (AN4401) and aspartate aminotransferase (AN1993). This is suggestive of degradation of asparagine into aspartate, followed by incorporation into the central carbon metabolism via oxaloacetate. Up-regulation of genes coding for glycogen debranching enzyme (AN10060) and $\beta$-glucosidase (AN10124), involved in the degradation of glycogen and glucans, respectively, points to the 


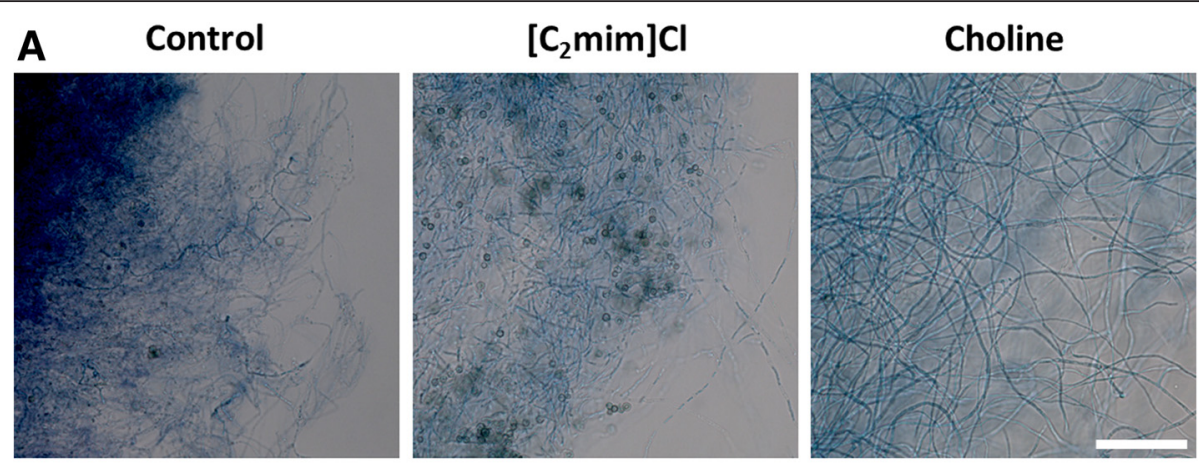

B Choline

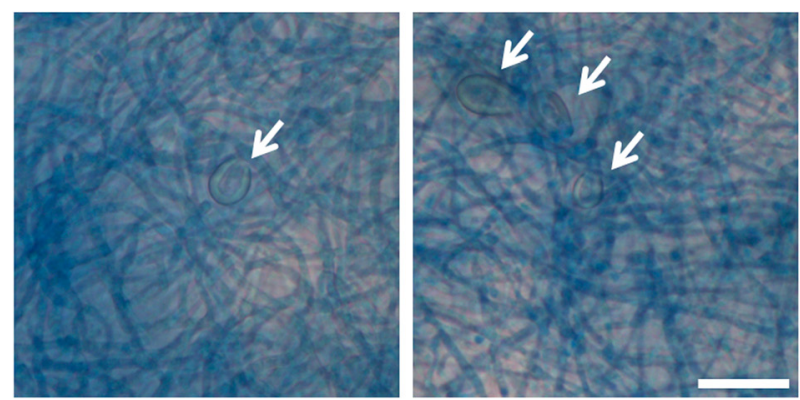

Fig. 3 Microscopic images of Aspergillus nidulans mycelia under ionic liquid stimuli. Images were collected at incubation day fifteen in the control medium or in either choline or 1-ethyl-3-methylimidazolium chloride ([C mim]Cl) supplemented media (a). In media supplemented with choline, formation of Hülle cells could be observed (white arrows) (b). Scale bars: $50 \mu \mathrm{m}$ (a); $30 \mu \mathrm{m}$ (b)

use of cellular reserves. The data suggest that carbohydrates originating from these reserves enter glycolysis/gluconeogenesis and are channelled to the pentose phosphate pathway (Fig. 4). 1-Ethyl-3-methylimidazolium chloride induced also the up-regulation of genes involved in the oxidative phase of the pentose phosphate pathway, 6phosphogluconolactonase (AN0285), 6-phosphogluconate dehydrogenases (AN6135 and AN10233) and ribulosephosphate 3-epimerase (AN7588) (Fig. 4). A similar effect was noticed before, although more evident in $N$. crassa than in A. nidulans [31]. Activation of this pathway leads probably to higher NADPH levels, which plays important roles in antioxidant defence [65].

Both ionic liquids apparently stimulated glutathione biosynthesis, known to play a key role in the stress response in filamentous fungi. This assumption is supported by the up-regulation of its biosynthetic genes, namely gamma-glutamyltranspeptidases genes (ggtA, AN10444; and AN5658) and gamma-cysteine synthetase regulatory subunit gene (AN2514) (Fig. 4, Table 2). Aspergillus nidulans up-accumulated a glutathione Stransferase in media supplemented with 1-ethyl-3-methylimidazolium chloride [31]. Glutathione S-conjugates are probably formed in the presence of either ionic liquid, shown here by the up-regulation of genes encoding glutathione S-transferases (AN3299 and AN6158) (Fig. 4, Table 2). Accordingly, we also observed that genes coding for efflux pumps (multidrug transporters) belonging to the ATP-binding cassette $(\mathrm{ABC})$ superfamily and the major facilitator superfamily (MFS) were up-regulated (Table 2). MFS multidrug transporters have been reported to participate in detoxification of 1-ethyl-3methylimidazolium chloride in Enterobacter lignolyticus [66]. Activation of both conjugation reactions and efflux pumps is most likely involved in the ionic liquids' detoxification processes in A. nidulans.

Both ionic liquids have possibly triggered the production of acetyl-CoA through pyruvate metabolism (pyruvate decarboxylase $p d c B$, AN8396; aldehyde dehydrogenase aldA,AN0554; and acetyl-CoA synthetase $f a c A$, AN5626) or the degradation of amino acids, such as branched amino acids (Fig. 4). Apart from being channelled to central metabolic pathways, acetyl-CoA is also a key precursor in the synthesis of numerous SMs, e.g. elongation of polyketide chains [67]. Also supporting production of SMs, we observed here the up-regulation of 1aminocyclopropane-1-carboxylate deaminase gene (AN8899) in either ionic liquid media. The encoded enzyme was not found in the mycelial proteome of $A$. nidulans cultures exposed to an ionic liquid, notwithstanding 1-aminocyclopropane-1-carboxylate deaminase accumulated in $N$. crassa grown in similar conditions [31]. Importantly, this enzyme mediates formation of the rare amino acid 1-aminocyclopropane-1-carboxylate found in 


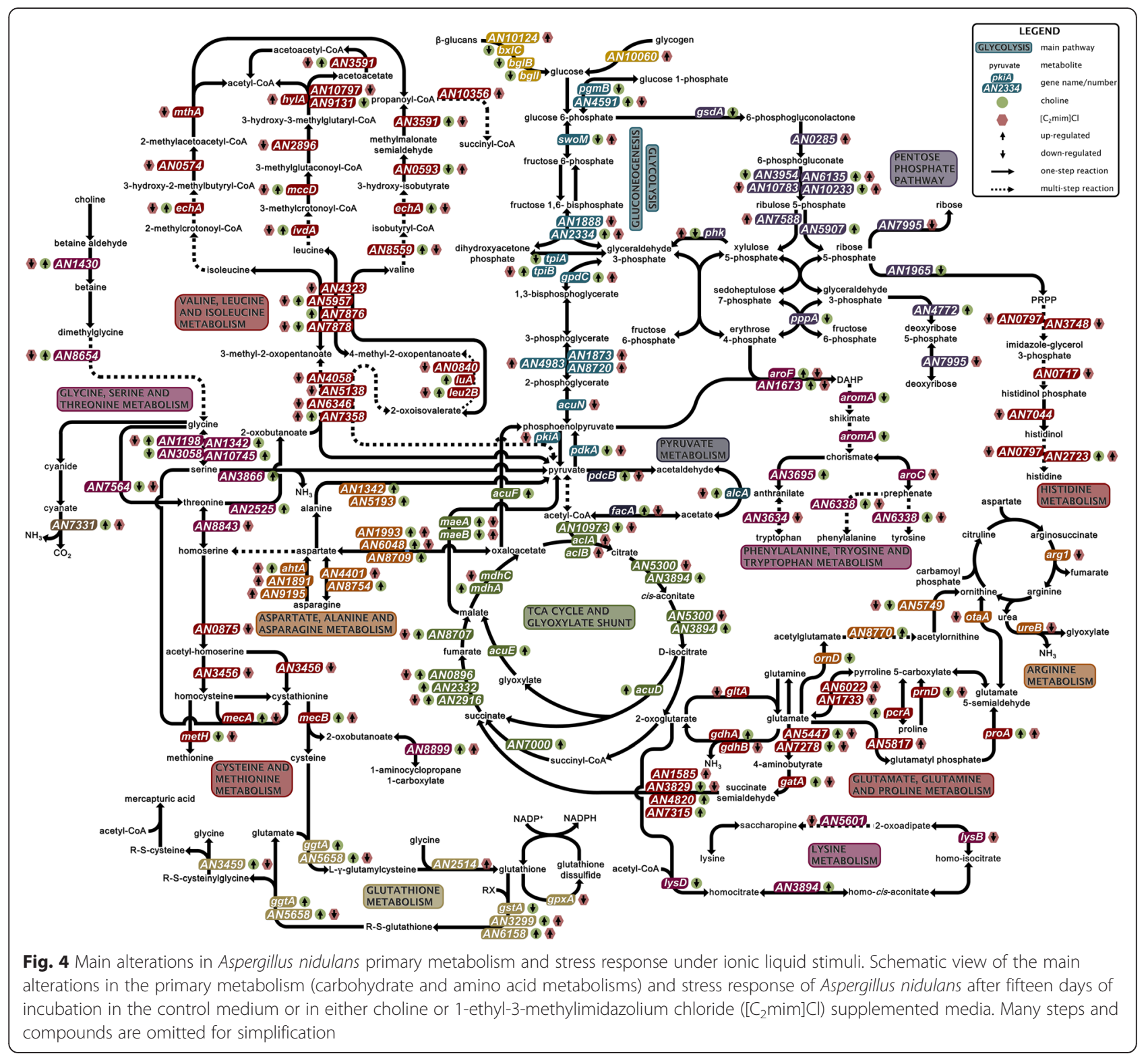

bioactive SMs classes such as neoefrapeptins and acretocins $[68,69]$.

Ionic liquids impact on secondary metabolism of $A$.

\section{nidulans - backbone genes}

Genes involved in biosynthesis of a particular SM are usually clustered and comprise the backbone gene responsible for biosynthesis of the metabolite core structure and genes coding for additional tailoring enzymes $[12,70]$. The backbone gene alone can be responsible for the production of a specific SM (e.g. microperfuranone [15] and orsellinic acid [17]), sometimes even when the expression of other clustered genes remains unaltered (e.g. penicillin [71]). Overexpression of backbone genes can also result in high production titres of certain SMs (e.g. alternariol [72]).

Consistent with the greater diversity of putative compounds found in cultures exposed to either ionic liquid (Table 1, Additional file 3), in total twenty one of the sixty six predicted backbone genes [3] were found upregulated compared to the control (Table 3 and Additional file 2). Fifteen and nine backbone genes were found up-regulated in choline and 1-ethyl-3methylimidazolium chloride supplemented media, respectively. This includes $m d p G$ in the choline medium and ors $A$ in both media. Only three genes coincided between the two conditions, suggesting each ionic liquid induces a specific stimulus. In addition to $m d p G$, the monodictyphenone cluster includes $m d p A$ (AN10021) 
Table 3 Secondary metabolite synthase genes up-regulated upon ionic liquid stimuli

\begin{tabular}{|c|c|c|c|c|c|}
\hline \multirow[b]{2}{*}{ GenelD } & \multirow[b]{2}{*}{ Gene } & \multicolumn{2}{|c|}{ Transcriptional profile* } & \multirow[b]{2}{*}{ Enzyme } & \multirow[b]{2}{*}{ Secondary metabolite } \\
\hline & & Choline & {$\left[\mathrm{C}_{2} \mathrm{mim}\right] \mathrm{Cl}$} & & \\
\hline AN0150 & $m d p G$ & 1.90 & -1.18 & PKS & monodictyphenone; emodin derivatives [4] \\
\hline AN0607 & sidC & 4.78 & -2.28 & NRPS & ferricrocin (siderophore) $[89,90]$ \\
\hline AN1594 & & 1.08 & 1.75 & DTS & ent-pimara-8(14),15-diene [91] \\
\hline AN10486 & & 1.52 & -1.19 & NRPS-like & \\
\hline AN11080 & nptA & 6.84 & -12.35 & DMATS & nidulanin A [14] \\
\hline AN11191 & & 1.83 & -1.27 & PKS & \\
\hline AN11820 & & -1.39 & 2.00 & NRPS-like & \\
\hline AN1680 & & 1.20 & 1.72 & NRPS-like & \\
\hline AN2064 & & 1.16 & 2.05 & NRPS-like & \\
\hline AN2547 & $e a s B$ & 2.80 & -2.67 & PKS & emericellamide [7] \\
\hline AN3230 & $p k f A$ & 1.02 & 1.78 & PKS & aspernidine A [11] \\
\hline AN3396 & micA & 1.80 & -1.04 & NRPS-like & microperfuranone [15] \\
\hline AN4827 & & 1.60 & 1.13 & NRPS-like & \\
\hline AN5318 & & 2.39 & 3.20 & NRPS & \\
\hline AN6236 & sidD & 1.52 & -2.80 & NRPS & triacetylfusarinine C (siderophore) [90] \\
\hline AN6784 & $x p t A$ & -1.53 & 1.88 & DMATS & prenyl xanthones [5] \\
\hline AN6791 & & 1.67 & 1.13 & PKS & \\
\hline AN7071 & $p k g A$ & 2.37 & 1.89 & PKS & alternariol; isocoumarins [72] \\
\hline AN12331 & & 1.86 & 1.56 & PKS-like & \\
\hline AN7909 & ors A & 1.61 & 1.35 & PKS & orsellinic acid; F9775A/B [17]; violaceols [43] \\
\hline AN9005 & & 6.81 & -2.28 & PKS & \\
\hline
\end{tabular}

Microarray analyses of the backbone genes up-regulated (fold-change, $\mathrm{FC}$ ) in choline or 1-ethyl-3-methylimidazolium chloride $\left(\left[\mathrm{C}_{2}\right.\right.$ mim $\left.] \mathrm{Cl}\right)$ supplemented media in pair-wise comparison with the control. Values highlighted in bold are statistically significant $(|\mathrm{FC}| \geq 1.5$ and $p$-value $\leq 0.05)$

*values highlighted in bold have $|\mathrm{FC}| \geq 1.5$ and $p$-value $\leq 0.05$ in the microarray data. NRPS = non-ribosomal peptide synthase; PKS = polyketide synthase; DMATS $=$ dimethylallyl tryptophan synthase (prenyltransferase); DTS = diterpene synthase

and $m d p E$ (AN0148), none of which underwent differential expression in choline media (Fig. 5a). These genes encode transcription factors required for full activation of the monodictyphenone cluster; their deletion usually decreases production titres of monodictyphenone, emodin and derivatives [4]. In addition, $m d p C$ and $m d p L$ were upregulated, consistent with monodictyphenone formation. The microarray data support the ability of choline supplement to stimulate formation of monodictyphenone, probably due to up-regulation of $m d p G$, especially since $c c l A$ expression levels remained unaltered (Additional file 2). De-repression of $m d p G$ increased significantly over time in choline supplemented media compared to control (Table 4), probably explaining monodictyphenone identification also on the fifth and tenth days of incubation (Table 1).

Only ors $A$ out of the three genes of the orsellinic acid cluster is necessary for the production of this metabolite [17]. Orsellinic acid detection is consistent with upregulation of ors $A$ in both ionic liquid supplemented media (Table 3), regardless of ors $B$ and ors $C$ expression values (Fig. 5b). ors $A$ underwent major up-regulation during exposure to either ionic liquid, although its expression was transient (Table 4). In the choline supplemented medium, the accumulation profile over time of orsellinic acid parallels ors $A$ expression (Table 1). In 1-ethyl-3methylimidazolium chloride medium, despite ors $A$ being more prominently up-regulated on the fifth day of incubation, this SM was detected only at longer incubation times (Table 1). The activities of the histone acetyltransferases EsaA (AN10956) [73] and GcnE (AN3621) [74] were reported to activate expression of penicillin, terrequinone A and sterigmatocystin gene clusters, whereas GcnE influences also ors $A$ expression. None of the ionic liquids led to differential expression of esaA and $g c n E$, or the backbone genes of penicillin, terrequinone $\mathrm{A}$ and sterigmatocystin (Additional file 2). In agreement, penicillin and sterigmatocystin were confirmed to be absent in the culture media (Additional file 3). Putative identification of terrequinone A only occurred in control cultures (data not shown), which may be explained by the major downregulation of its backbone gene in both ionic liquid media (Additional file 2). None of the identified ion masses matched compounds assigned to the remaining upregulated backbone genes (Table 3), probably because 

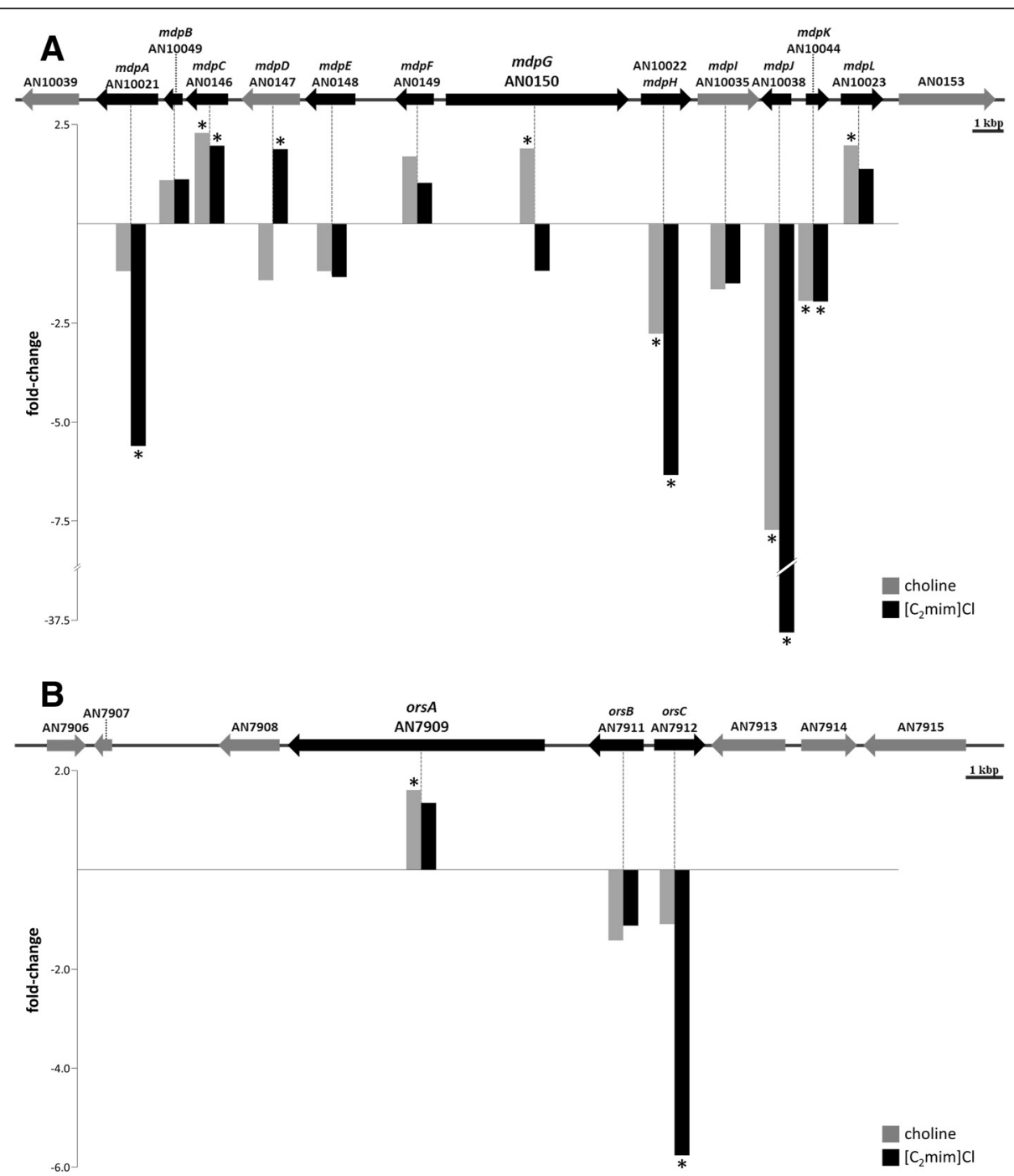

Fig. 5 Expression profile of component genes of the monodictyphenone and orsellinic acid clusters under ionic liquid stimuli. Representation of the gene clusters involved in the biosynthesis of monodictyphenone (a) and orsellinic acid (b) in Aspergillus nidulans. Essential and non-essential genes are shown in black and grey (arrows), respectively (adapted from $[4,37])$. Below each gene the measured fold-change (FC) in either choline or 1-ethyl-3-methylimidazolium chloride $\left(\left[\mathrm{C}_{2} \mathrm{mim}\right] \mathrm{Cl}\right)$ supplemented media are depicted (microarray data) and, if statistically significant ( $|\mathrm{FC}| \geq 1.5$ and $p$-value $\leq 0.05)$, indicated with an asterisk $\left(^{*}\right)$

their abundance is below the detection limit or accumulated intracellularly, or other yet uncharacterised metabolites from the cluster were produced instead.

\section{Ionic liquids impact on secondary metabolism of $A$.} nidulans - regulatory genes

A complex regulatory network governs the co-regulation of the clustered SM biosynthetic genes [75], involving hierarchical levels of transcriptional regulatory elements. These can be either pathway-specific (e.g. AflR in the sterigmatocystin/aflatoxin gene cluster [76]) or broad domain transcription factors (e.g. the Velvet complex), and proteins responsive to general environmental factors that are also implicated in cluster activation (e.g. CreA,
PacC and AreA) [77]. Global regulators of secondary metabolism in Aspergillus spp. include the well-studied VelB/VeA/LaeA transcriptional complex (i.e. Velvet complex) that links secondary metabolism with fungal development $[75,78]$. In the dark - similar to culture conditions used here - the Velvet complex controls the activity of LaeA (methyltransferase-domain nuclear protein), which in turn controls the expression of several SM gene clusters $[79,80]$. The impact of LaeA on the regulation of secondary metabolism has been well studied in A. fumigatus (the laeA deletion mutant shows repression of 13 of $22 \mathrm{SM}$ biosynthetic clusters) [81], but is also known to impact other fungi (e.g. Fusarium verticillioides [82]). It controls, in general, gene clusters 
Table 4 Time-course analysis of gene expression of orsellinic acid and monodictyphenone synthases and major regulators

\begin{tabular}{|c|c|c|c|c|c|}
\hline \multirow[b]{2}{*}{ Media } & \multirow[b]{2}{*}{ GenelD } & \multirow[b]{2}{*}{ Gene } & \multicolumn{3}{|c|}{$q R T-P C R^{a}$} \\
\hline & & & $5 d$ & $10 d$ & $15 d$ \\
\hline \multirow[t]{5}{*}{ Choline } & AN7909 & ors $A$ & 2.04 & -3.62 & 1.49 \\
\hline & AN0150 & $m d p G$ & -57.33 & -44.94 & -2.66 \\
\hline & AN0807 & laeA & -10.09 & -4.32 & -10.00 \\
\hline & AN4562 & $r s m A$ & -1.64 & 1.43 & 2.30 \\
\hline & AN1052 & veA & -2.91 & -1.77 & -1.00 \\
\hline \multirow[t]{5}{*}[\mathrm{C}_{2}\mathrm{mim}]{$\mathrm{Cl}$} & AN7909 & ors $A$ & 24.65 & 1.29 & 3.42 \\
\hline & AN0150 & $m d p G$ & -5.54 & -74.07 & -39.50 \\
\hline & AN0807 & laeA & -6.93 & -13.87 & -31.40 \\
\hline & AN4562 & $r s m A$ & 1.94 & -2.02 & 1.09 \\
\hline & AN1052 & veA & -4.14 & -6.85 & 1.65 \\
\hline
\end{tabular}

qRT-PCR analysis of the expression of ors $A$ and $m d p G$ (backbone genes of orsellinic acid and monodictyphenone, respectively), and laeA, veA and rsmA (secondary metabolism regulatory genes) along the incubation time in choline or 1-ethyl-3-methylimidazolium chloride $\left(\left[\mathrm{C}_{2} \mathrm{mim}\right] \mathrm{Cl}\right)$ supplemented media. Values represent relative gene expression at each culture time in pair-wise comparisons with the control. Expression of each gene was normalised to the expression of the histone protein $\mathrm{H} 3$ gene (AN0733)

${ }^{\text {a }}$ Fold changes (FCs) in pair-wise comparison with the control

positioned at the telomere proximal region of the chromosomes [83]. Among the backbone genes found upregulated here only few are located proximal to the telomere, consistent with studies implicating other secondary metabolism regulatory elements apart from LaeA [15].

LaeA (AN0807) is required for biosynthesis of sterigmatocystin and penicillin [78]. However, sterigmatocystin biosynthesis can be restored in laeA or veA deletion strains by the up-regulation of $r s m A$ (remediation of secondary metabolism $A$, AN4562) [84] or the deletion of $m t f A$ (master transcription factor $A$, AN8741) [85], respectively. Our microarray data showed that both ionic liquids led to down-regulation of laeA, whereas veA (AN1052) was down-regulated only in 1-ethyl-3-methylimidazolium chloride supplemented medium and velB (AN0363) was not differentially expressed in either condition (Table 5). qRT-PCR analyses of expression levels of $l a e A$ and $v e A$ over the incubation period (up to fifteen days) confirmed their down-regulation (Table 4). In choline supplemented medium, despite the up-regulation of rsmA over time (Table 4) sterigmatocystin accumulation was not validated (Additional file 3). In addition, upregulation of $m t f A$ in 1-ethyl-3-methylimidazolium chloride medium likely led to the down-regulation of sterigmatocystin and terrequinone $\mathrm{A}$ backbone genes (Additional file 2), hence the absence of these SMs in the cultures. Penicillin accumulation in the culture was not observed, consistent with the down-regulation of laeA, which is required for its biosynthesis [78].

Additional genes involved in histone modifications can also impact SM production. Deletion of the histone deacetylase gene $h d a A$ (AN8042) for example induces the production of sterigmatocystin and penicillin [86] and high levels of the heterochromatin protein HepA (AN1905) provoke opposite effects [87]. hdaA was not differentially expressed but hepA was up-regulated in 1-ethyl-3-methylimidazolium chloride supplemented medium (Table 5), probably contributing to the repression of sterigmatocystin and penicillin biosynthesis in this medium.

A set of thirteen genes involved in secondary metabolism, either coding for SM synthases $(m d p G$, ors $A, \operatorname{sid} C$, eas $B$ and ausA), chromatin remodelling enzymes (hepA, $h d a A$ and $g c n E$ ) or regulatory proteins, including those discussed above (laeA, rsmA, veA and velB), as well as $f l u G$, were selected to validate the microarray data by $q$ RT-PCR (Table 5). With few exceptions the majority of the analysed genes displayed an expression profile similar to that detected by microarray analyses.

\section{Analysis of the biological activity of $A$. nidulans metabolite extracts after ionic liquid stimuli}

To screen the presence of compounds displaying anticarcinoma potential in the metabolite extracts of $A$. nidulans an ex vivo polarity modulation assay $\left(\right.$ the $\left.\mathrm{LiTE}^{\mathrm{mm}}\right)$ was used. The positive control ( $30 \mu \mathrm{M}$ of the-103 compound) affected $100 \%$ of the Drosophila eggs, whereas

Table 5 qRT-PCR analysis of selected genes encoding secondary metabolism components, either biosynthesis or regulation

\begin{tabular}{|c|c|c|c|c|c|}
\hline \multirow[b]{2}{*}{ GenelD } & \multirow[b]{2}{*}{ Gene } & \multicolumn{2}{|l|}{ Choline } & \multicolumn{2}{|c|}{$\left[\mathrm{C}_{2} \mathrm{mim}\right] \mathrm{Cl}$} \\
\hline & & qRT-PCR & Microarray ${ }^{*}$ & qRT-PCR & Microarray* \\
\hline \multicolumn{6}{|c|}{ Backbone genes } \\
\hline AN7909 & ors A & 1.67 & 1.61 & 2.57 & 1.35 \\
\hline AN0150 & $m d p G$ & -3.62 & 1.90 & -12.50 & -1.18 \\
\hline AN8383 & ausA & -6.00 & -1.30 & -3.04 & -2.26 \\
\hline AN2547 & eas $B$ & 2.08 & 2.80 & -4.92 & -2.67 \\
\hline AN0607 & sidC & 3.06 & 4.78 & -4.57 & -2.28 \\
\hline \multicolumn{6}{|c|}{ Transcriptional regulators } \\
\hline AN0807 & laeA & -6.75 & -6.71 & -25.32 & -17.55 \\
\hline AN1052 & veA & -1.08 & -1.23 & -1.23 & -1.52 \\
\hline AN0363 & velB & -1.91 & -1.16 & 1.43 & 1.45 \\
\hline AN4819 & fluG & -1.26 & -1.12 & -1.89 & -1.45 \\
\hline AN4562 & $r s m A$ & -1.21 & 1.12 & -1.66 & -1.18 \\
\hline AN1905 & hepA & -1.06 & 1.18 & 1.23 & 1.70 \\
\hline AN8042 & hdaA & 1.39 & 1.04 & 1.14 & -1.18 \\
\hline AN3621 & gcnE & 1.14 & -1.34 & 1.26 & -1.30 \\
\hline
\end{tabular}

Values represent the relative expression of selected genes in pair-wise comparisons with the control, after fifteen days of incubation. Expression of each gene was normalised to the expression of the histone protein $\mathrm{H} 3$ gene (AN0733). Corresponding microarray data are shown for comparison *values highlighted in bold have $|\mathrm{FC}| \geq 1.5$ and $p$-value $\leq 0.05$ in the microarray data 
A
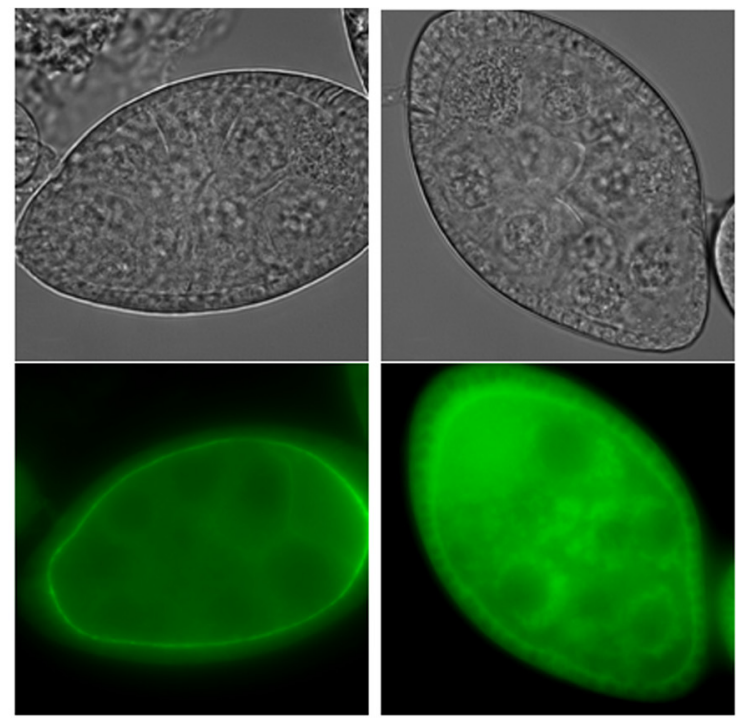

Blank solution

the-103

B
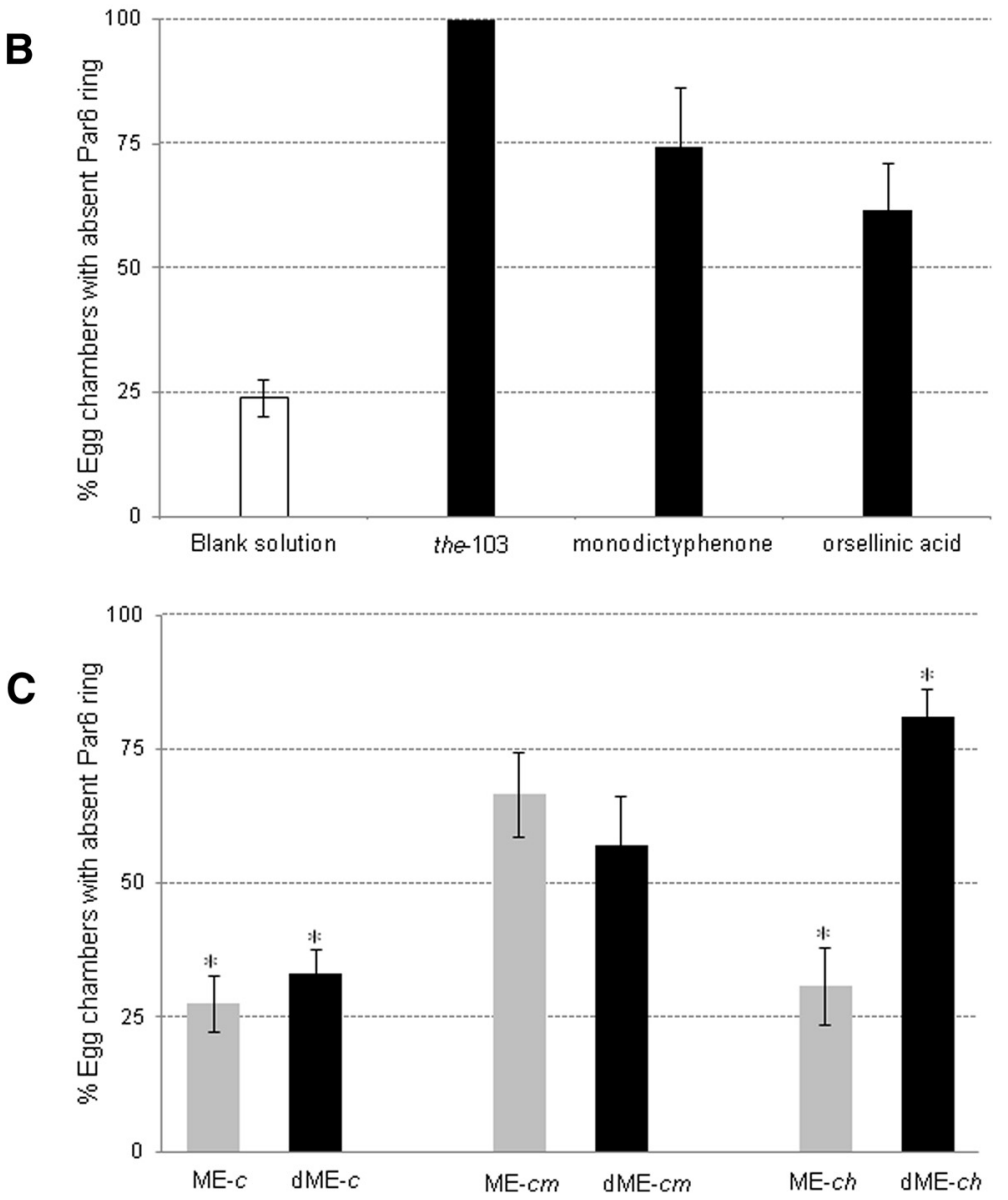

Fig. 6 Ex vivo theLiTE ${ }^{T M}$ assay of Aspergillus nidulans metabolite extracts from ionic liquid supplemented media. Microscope image of Drosophila egg chambers showing presence/absence of the polarity marker protein Par6 when exposed to solvent only solution ( $0.6 \%$ DMSO, i.e. blank) and the-103, respectively (a); \% of egg chambers showing Par6 ring impairment in the presence of $24 \mu \mathrm{g} / \mathrm{mL}$ monodictyphenone, orsellinic acid, the-103 (the blank is also shown) (b) or metabolite extracts collected at incubation day seven in the control medium (ME-c) or either choline (ME-ch) or 1-ethyl-3-methylimidazolium chloride $\left(\left[\mathrm{C}_{2} \mathrm{mim}\right] \mathrm{Cl}\right)(\mathrm{ME}-\mathrm{cm})$ supplemented media, before (grey bars) or after dereplication of its polar fraction (dME) (black bars) (c). The asterisk denotes a significant difference $(p$-value $\leq 0.05)$ of each treatment compared to the control 
the blank (i.e. $0.6 \% \mathrm{v} / \mathrm{v}$ DMSO which is the solution used to solubilise the metabolite extracts) is devoid of any significant activity (Fig. 6a-b). The capacity of a pure compound to impair the fluorescent ring of the polarity marker protein Par6 in more than ca. 50 \% of the eggs is defined as the empirical cut off for a positive result. When dealing with complex mixtures, much weaker activities should be regarded as significant, especially if a de-replicated fraction shows substantially higher activity. Under standard cultivation conditions (control), metabolite extracts (crude and its corresponding polar fraction) were virtually devoid of activity (Fig. 6c); both ionic liquids induced the biosynthesis of compounds carrying anti-carcinoma potential. Similar activities were, in general, measured for the metabolite extracts derived in either ionic liquid media at the seventh or the fifteenth day of incubation, which were much stronger that those measured at the second day (data not shown). For example, crude metabolite extracts $(24 \mu \mathrm{g} / \mathrm{mL})$ from 1ethyl-3-methylimidazolium chloride and choline supplemented media, at the seventh day of incubation, showed high to moderate activity (67 and $31 \%$, respectively); their polar fractions (de-replicated metabolite extracts, dME) showed similar or much greater activity (57 and $81 \%$, respectively) (Fig. 6c). The detected activities cannot be related to any vestigial amounts of either ionic liquid, because these compounds per se lack activity (data not shown). We verified also that $24 \mu \mathrm{g} / \mathrm{mL}$ of monodictyphenone $(83 \mu \mathrm{M})$ or orsellinic acid $(129 \mu \mathrm{M})$ affected 75 or $62 \%$ of the eggs, respectively (Fig. 6b). Both SMs, primarily monodictyphenone, may contribute to the polarity modulating activity of the metabolite extracts (either crude or de-replicated); additional active components probably remain obscured. The future challenge is to identify, among the compounds specific to each ionic liquid, those that carry intrinsic anti-carcinoma activity.

\section{Conclusions}

Transcriptional profiling was used for the first time to evaluate ionic liquids broad impacts on both primary and secondary metabolism of $A$. nidulans. Primary metabolism was up-regulated by choline, but downregulated by 1-ethyl-3-methylimidazolium chloride. Choline could be used as a source of carbon and nitrogen probably via the glycine, serine and threonine metabolic pathway, and incorporated into the central carbon metabolism. On the contrary, the recalcitrant 1-ethyl-3methylimidazolium chloride induced the use of cellular reserves and autophagy. Both ionic liquids induced detoxification mechanisms (viz. multidrug transporters and glutathione S-conjugates) probably to eliminate the toxic cations or toxic intermediates (e.g. cyanide). Despite strongly contrasting effects on primary metabolism either ionic liquid apparently stimulated production of acetyl-CoA, a key precursor to numerous SMs, as well as the production of non proteinogenic amino acids known as building blocks of bioactive classes of SMs. Differential analyses of the fungal metabolome allowed discovery of numerous putative SMs, including gentisic acid and caffeic acid here reported for the first time in $A$. nidulans. Concurrently with numerous differentially formed compounds, multiple genes encoding SM biosynthetic enzymes were up-regulated. Each ionic liquid stimulus activated a specific set of backbone genes, including uncharacterised ones. In addition, growth media supplementation with choline led, for the first time, to monodictyphenone accumulation in a wild type strain of A. nidulans. Importantly, we observed here that the complex mixtures of the formed metabolites camouflage compounds with anti-carcinoma potential. This study should inspire the search of novel bioactive fungal SMs biosynthesised under an ionic liquid stimulus.

Ionic liquids impact on eukaryotic organisms constitutes a fundamental cue for conscious development of this field. This study constitutes a step forward to prior proteomic analyses of ionic liquids' impacts in primary metabolism, providing a more detailed analysis and expanding initial findings to secondary metabolism. We believe it illustrates the potential of ionic liquids to induce metabolic alterations and stress responses in eukaryotic organisms. In particular, we showed that they can be used to further resolve the diversity of natural compounds, guiding discovery of fungal metabolites with clinical potential. Further studies are necessary to elucidate the capacity of the ionic components to specifically modulate defined response regulators of metabolism and development in fungi. Ionic liquids formation during the confrontation between two ant species has been recently demonstrated, probably as a defence mechanism [88]. The likelihood of natural ionic liquids creates a new paradigm - they are not exclusively man-made chemicals - and supplies a new boost of interest in their research. Unforeseen possibilities have been revealed and future exploration promises to be exciting.

\section{Availability of supporting data}

Data sets supporting the results of this article are included within the article (and its additional files).

\section{Additional files}

Additional file 1: Microarray additional details, experimental data and validation. (PDF 649 kb)

Additional file 2: Microarray raw data and list of differentially expressed genes. (XLSX $3421 \mathrm{~kb}$ )

Additional file 3: List of all the differential compounds identified in the culture extracts. (XLSX 107 kb) 


\section{Abbreviations}

FC: fold change; MIPS: Munich Information Center for Protein Sequences; qRT-PCR: quantitative real-time PCR; SMs: secondary metabolites; TCA: tricarboxylic acid cycle; UHPLC-ESI-HRMS: ultra-high performance liquid chromatography-electrospray ionisation-high resolution mass spectrometry.

\section{Competing interests}

Non-financial competing interests. $\mathrm{RH}$ is founder and share-holder of Thelial Technologies S.A.

\section{Authors' contributions}

CSP supervised the project and the interpretation of data and prepared the final version of the manuscript. All authors have made substantial contributions to the acquisition, analysis and interpretation of data and contributed to the drafting of the manuscript: PCA and IM (experimental set up), PCA and JDB (transcriptome analyses), ON and MTG (metabolome analyses), TLG and RH (biological assays), DOH (PCR analyses and microscopy studies), HG and JDB (statistics), PCA and DOH (preparation of the initial draft of the manuscript). All authors read and approved the final version of the manuscript.

\section{Authors' information}

This research constitutes an important milestone for C. Silva Pereira's team (established in 2008) that is addressing a major scientific question: How fungi perceive and interact with the environment? What makes our research approach distinctive is the merger of fundamental biology research with chemical expertise. Such a multidisciplinary environment has inspired the application of ionic liquids in biological sciences research. While initial studies focussed on their toxicity towards filamentous fungi, we are now exploring their function as unique stimuli to address knowledge gaps in secondary metabolism and signalling pathways, impacting on fungal pathogenicity and development. Task-designed ionic liquids provided us with an entry point for use of suberin macromolecules - which self-assemble ex situ as biocidal films - to investigate how this plant polyester impacts on fungal development (BMC Genomics, 2014, 15). We are particularly interested in using our acquired knowledge to develop novel and efficient antifungal strategies. The need for novel antifungals is massive and growing, emerging fungal pathogens are globally a major cause of mortality in the immunocompromised patient populations, and the current pace of antifungal drug development is simply too pedestrian to keep up.

\section{Acknowledgements}

We acknowledge funding from the European Research Council through grant ERC-2014-CoG-647928, FCT through grants UID/Multi/04551/2013 (Research unit GREEN-it "Bioresources for Sustainability"), PTDC/QUI-QUI/ 120982/2010 and PTDC/AAC-CLI/119100/2010. We also acknowledge funding provided by the Spanish Ministry of Economy and Competitiveness under the project CTQ2012-30836 and by the Agency for Administration of University and Research Grants (Generalitat de Catalunya, Spain) under the project 2014 SGR-539. The authors would like to acknowledge the kind support in the framework of the COST Action EXIL - Exchange on lonic Liquids (CM1206). PCA and IM are grateful to Fundação para a Ciência e a Tecnologia (FCT), Portugal, for the fellowships, SFRH/BD/66030/2009 and SFRH/BPD/110841/2015, respectively, and CSP for the development contract grant IF/00713/2013. The authors thank Eng. $M^{a}$ Cristina Leitão (ITQB) for technical support. We are grateful to Dr. Agnieszka Wozniak and Prof. Thomas J. Simpson (University of Bristol, UK) for kindly providing the monodictyphenone standard and Prof. Olov Sterner (Lund University) for providing scientific mentoring. Thelial extends its thanks to CEDOC for infrastructure support.

\footnotetext{
Author details

'Instituto de Tecnologia Química e Biológica António Xavier, Universidade Nova de Lisboa, Av. da República, 2780-157 Oeiras, Portugal. ²Department of Analytical Chemistry, University of Barcelona, Diagonal 645, E-08028 Barcelona, Spain. ${ }^{3}$ Serra Hunter Fellow, Generalitat de Catalunya, Barcelona, Spain. ${ }^{4}$ Thelial Technologies S.A., Parque Tecnológico de Cantanhede, Nucleo 04 Lote 3, 3060-197 Cantanhede, Portugal. ${ }^{5}$ Instituto Gulbenkian de Ciência, Rua da Quinta Grande 6, 2780-156 Oeiras, Portugal.
}

Received: 1 December 2015 Accepted: 8 March 2016 Published online: 12 April 2016

\section{References}

1. Bok JW, Hoffmeister D, Maggio-Hall LA, Murillo R, Glasner JD, Keller NP. Genomic mining for Aspergillus natural products. Chem Biol. 2006;13(1):31-7.

2. Brakhage AA. Regulation of fungal secondary metabolism. Nat Rev Microbiol. 2013;11(1):21-32.

3. Inglis DO, Binkley J, Skrzypek MS, Arnaud MB, Cerqueira GC, Shah P, Wymore F, Wortman JR, Sherlock G. Comprehensive annotation of secondary metabolite biosynthetic genes and gene clusters of Aspergillus nidulans, A. fumigatus, A. niger and A. oryzae. BMC Microbiol. 2013;13:91.

4. Chiang YM, Szewczyk E, Davidson AD, Entwistle R, Keller NP, Wang CCC, Oakley BR. Characterization of the Aspergillus nidulans monodictyphenone gene cluster. Appl Environ Microbiol. 2010;76(7):2067-74.

5. Sanchez JF, Entwistle R, Hung JH, Yaegashi J, Jain S, Chiang YM, Wang CCC, Oakley BR. Genome-based deletion analysis reveals the prenyl xanthone biosynthesis pathway in Aspergillus nidulans. J Am Chem Soc. 2011;133(11): 4010-7.

6. Chiang YM, Lee KH, Sanchez JF, Keller NP, Wang CCC. Unlocking fungal cryptic natural products. Nat Prod Commun. 2009;4(11):1505-10.

7. Chiang YM, Szewczyk E, Nayak T, Davidson AD, Sanchez JF, Lo HC, Ho WY, Simityan $\mathrm{H}$, Kuo E, Praseuth A, et al. Molecular genetic mining of the Aspergillus secondary metabolome: discovery of the emericellamide biosynthetic pathway. Chem Biol. 2008;15(6):527-32.

8. Bergmann S, Schümann J, Scherlach K, Lange C, Brakhage AA, Hertweck C. Genomics-driven discovery of PKS-NRPS hybrid metabolites from Aspergillus nidulans. Nat Chem Biol. 2007;3(4):213-7.

9. Szewczyk E, Chiang YM, Oakley CE, Davidson AD, Wang CCC, Oakley BR. Identification and characterization of the asperthecin gene cluster of Aspergillus nidulans. Appl Environ Microbiol. 2008;74(24):7607-12.

10. Bouhired S, Weber M, Kempf-Sontag A, Keller NP, Hoffmeister D. Accurate prediction of the Aspergillus nidulans terrequinone gene cluster boundaries using the transcriptional regulator LaeA. Fungal Genet Biol. 2007;44(11):1134-45.

11. Yaegashi J, Praseuth MB, Tyan SW, Sanchez JF, Entwistle R, Chiang YM Oakley BR, Wang CC. Molecular genetic characterization of the biosynthesis cluster of a prenylated isoindolinone alkaloid aspernidine A in Aspergillus nidulans. Org Lett. 2013;15(11):2862-5.

12. Brown DW, Yu JH, Kelkar HS, Fernandes M, Nesbitt TC, Keller NP, Adams TH, Leonard TJ Twenty-five coregulated transcripts define a sterigmatocystin gene cluster in Aspergillus nidulans. Proc Natl Acad Sci U S A. 1996;93(4):1418-22.

13. Kennedy J, Turner G. delta-(L-alpha-aminoadipyl)-L-cysteinyl-D-valine synthetase is a rate limiting enzyme for penicillin production in Aspergillus nidulans. Mol Gen Genet. 1996;253(1-2):189-97.

14. Andersen MR, Nielsen JB, Klitgaard A, Petersen LM, Zachariasen M, Hansen TJ, Blicher LH, Gotfredsen CH, Larsen TO, Nielsen KF. Accurate prediction of secondary metabolite gene clusters in filamentous fungi. Proc Natl Acad Sci U S A. 2013;110(1):E99-107.

15. Yeh H-H, Chiang Y-M, Entwistle R, Ahuja M, Lee K-H, Bruno KS, Wu T-K, Oakley BR, Wang CCC. Molecular genetic analysis reveals that a nonribosomal peptide synthetase-like (NRPS-like) gene in Aspergillus nidulans is responsible for microperfuranone biosynthesis. Appl Microbiol Biotechnol. 2012;96(3):739-48.

16. Sanchez JF, Entwistle R, Corcoran D, Oakley BR, Wang CC. Identification and molecular genetic analysis of the cichorine gene cluster in Aspergillus nidulans. Med Chem Comm. 2012;3(8):997-1002.

17. Sanchez JF, Chiang Y-M, Szewczyk E, Davidson AD, Ahuja M, Oakley CE, Bok JW, Keller N, Oakley BR, Wang CCC. Molecular genetic analysis of the orsellinic acid/F9775 gene cluster of Aspergillus nidulans. Molecular Biosystems. 2010;6(3):587-93.

18. Lo HC, Entwistle R, Guo CJ, Ahuja M, Szewczyk E, Hung JH, Chiang YM, Oakley BR, Wang CC. Two separate gene clusters encode the biosynthetic pathway for the meroterpenoids austinol and dehydroaustinol in Aspergillus nidulans. J Am Chem Soc. 2012;134(10):4709-20.

19. Chiang YM, Ahuja M, Oakley CE, Entwistle R, Asokan A, Zutz C, Wang CC, Oakley BR. Development of genetic dereplication strains in Aspergillus nidulans results in the discovery of aspercryptin. Angew Chem Int Ed Engl. 2016;55(5):1662-5.

20. Giles SS, Soukup AA, Lauer C, Shaaban M, Lin A, Oakley BR, Wang CCC, Keller NP. Cryptic Aspergillus nidulans antimicrobials. Appl Environ Microbiol. 2011;77(11):3669-75 
21. Evans BS, Robinson SJ, Kelleher NL. Surveys of non-ribosomal peptide and polyketide assembly lines in fungi and prospects for their analysis in vitro and in vivo. Fungal Genet Biol. 2011;48(1):49-61.

22. Yaegashi J, Oakley BR, Wang CCC. Recent advances in genome mining of secondary metabolite biosynthetic gene clusters and the development of heterologous expression systems in Aspergillus nidulans. J Ind Microbiol Biotechnol. 2014;41(2):433-42.

23. Scherlach $K$, Hertweck $C$. Discovery of aspoquinolones $A-D$, prenylated quinoline-2-one alkaloids from Aspergillus nidulans, motivated by genome mining. Org Biomol Chem. 2006;4(18):3517-20.

24. Bok JW, Chiang YM, Szewczyk E, Reyes-Domingez Y, Davidson AD, Sanchez JF, Lo HC, Watanabe K, Strauss J, Oakley BR, et al. Chromatin-level regulation of biosynthetic gene clusters. Nat Chem Biol. 2009;5(7):462-4.

25. Oh DC, Kauffman CA, Jensen PR, Fenical W. Induced production of emericellamides A and B from the marine-derived fungus Emericella sp. in competing co-culture. J Nat Prod. 2007;70(4):515-20.

26. Yin $Y, X u B, L i$ Z, Zhang B. Enhanced production of (+)-terrein in fed-batch cultivation of Aspergillus terreus strain PF26 with sodium citrate. World J Microbiol Biotechnol. 2013;29(3):441-6.

27. Henrikson JC, Hoover AR, Joyner PM, Cichewicz RH. A chemical epigenetics approach for engineering the in situ biosynthesis of a cryptic natural product from Aspergillus niger. Org Biomol Chem. 2009;7(3):435-8.

28. Petkovic M, Ferguson JL, Bohn A, Trindade J, Martins I, Carvalho MB, Leitão MC, Rodrigues C, Garcia H, Ferreira R, et al. Exploring fungal activity in the presence of ionic liquids. Green Chem. 2009;11(6):889-94.

29. Petkovic M, Seddon KR, Rebelo LPN, Silva Pereira C. Ionic liquids: a pathway to environmental acceptability. Chem Soc Rev. 2011;40(3):1383-403.

30. Plechkova NV, Seddon KR. Applications of ionic liquids in the chemical industry. Chem Soc Rev. 2008;37(1):123-50.

31. Martins I, Hartmann DO, Alves PC, Planchon S, Renaut J, Leitao C, Rebelo LPN, Silva Pereira C. Proteomic alterations induced by ionic liquids in Aspergillus nidulans and Neurospora crassa. J Proteomics. 2013;94C:262-78.

32. Martins I, Hartmann DO, Alves PC, Martins C, Garcia H, Leclercq CC, Ferreira R, He J, Renaut J, Becker JD, et al. Elucidating how the saprophytic fungus Aspergillus nidulans uses the plant polyester suberin as carbon source. BMC Genomics. 2014;15:613.

33. Simpson TJ. Genetic and biosynthetic studies of the fungal prenylated xanthone shamixanthone and related metabolites in Aspergillus spp. revisited. ChemBioChem. 2012;13(11):1680-8.

34. Edgar R, Domrachev M, Lash AE. Gene expression omnibus: NCBI gene expression and hybridization array data repository. Nucleic Acids Res. 2002;30(1):207-10.

35. Li C, Hung Wong W. Model-based analysis of oligonucleotide arrays: model validation, design issues and standard error application. Genome Biol. 2001;2(8):RESEARCH0032.

36. Li C, Wong WH. Model-based analysis of oligonucleotide arrays: expression index computation and outlier detection. Proc Natl Acad Sci U S A. 2001;98(1):31-6.

37. Smyth GK. Linear models and empirical bayes methods for assessing differential expression in microarray experiments. Stat Appl Genet Mol Biol. 2004;3(1):Article3.

38. Priebe S, Linde J, Albrecht D, Guthke R, Brakhage AA. FungiFun: a webbased application for functional categorization of fungal genes and proteins. Fungal Genet Biol. 2011;48(4):353-8.

39. Martins I, Garcia H, Varela A, Núñez O, Planchon S, Galceran MT, et al. Investigating Aspergillus nidulans secretome during colonisation of cork cell walls. J Proteomics. 2013;98:175-88.

40. Krause C, Kirschbaum J, Brückner H. Peptaibiomics: an advanced, rapid and selective analysis of peptaibiotics/peptaibols by SPE/LC-ES-MS. Amino Acids. 2006:30(4):435-43.

41. Regala RP, Thompson EA, Fields AP. Atypical protein kinase C iota expression and aurothiomalate sensitivity in human lung cancer cells. Cancer Res. 2008;68(14):5888-95.

42. Diano A, Bekker-Jensen S, Dynesen J, Nielsen J. Polyol synthesis in Aspergillus niger: influence of oxygen availability, carbon and nitrogen sources on the metabolism. Biotechnol Bioeng. 2006;94(5):899-908.

43. Nielsen ML, Nielsen JB, Rank C, Klejnstrup ML, Holm DK, Brogaard KH, Hansen BG, Frisvad JC, Larsen TO, Mortensen UH. A genome-wide polyketide synthase deletion library uncovers novel genetic links to polyketides and meroterpenoids in Aspergillus nidulans. FEMS Microbiol Lett. 2011;321(2):157-66.
44. Nahlik K, Dumkow M, Bayram O, Helmstaedt K, Busch S, Valerius O, Gerke J, Hoppert M, Schwier E, Opitz L, et al. The COP9 signalosome mediates transcriptional and metabolic response to hormones, oxidative stress protection and cell wall rearrangement during fungal development. Mol Microbiol. 2010;78(4):964-79.

45. Blunt JW, Copp BR, Keyzers RA, Munro MHG, Prinsep MR. Marine natural products. Nat Prod Rep. 2013;30(2):237-323.

46. Nielsen KF, Mogensen JM, Johansen M, Larsen TO, Frisvad JC. Review of secondary metabolites and mycotoxins from the Aspergillus niger group. Anal Bioanal Chem. 2009;395(5):1225-42.

47. Raistrick $H$, Simonart P. Studies in the biochemistry of micro-organisms: 2:5-Dihydroxybenzoic acid (gentisic acid) a new product of the metabolism of glucose by Penicillium griseo-fulvum Dierckx. Biochem J. 1933;27(3):628-33.

48. Nielsen KF, Smedsgaard J. Fungal metabolite screening: database of 474 mycotoxins and fungal metabolites for dereplication by standardised liquid chromatography-UV-mass spectrometry methodology. J Chromatogr A. 2003;1002(1-2):111-36.

49. Schroeckh $V$, Scherlach $K$, Nützmann H-W, Shelest E, Schmidt-Heck W, Schuemann J, Martin K, Hertweck C, Brakhage AA. Intimate bacterial-fungal interaction triggers biosynthesis of archetypal polyketides in Aspergillus nidulans. Proc Natl Acad Sci U S A. 2009;106(34):14558-63.

50. Sarkar A, Funk AN, Scherlach K, Horn F, Schroeckh V, Chankhamjon P, Westermann M, Roth M, Brakhage AA, Hertweck C, et al. Differential expression of silent polyketide biosynthesis gene clusters in chemostat cultures of Aspergillus nidulans. J Biotechnol. 2012;160(1-2):64-71.

51. Han KH, Prade RA. Osmotic stress-coupled maintenance of polar growth in Aspergillus nidulans. Mol Microbiol. 2002;43(5):1065-78.

52. Furukawa K, Hoshi Y, Maeda T, Nakajima T, Abe K. Aspergillus nidulans HOG pathway is activated only by two-component signalling pathway in response to osmotic stress. Mol Microbiol. 2005;56(5):1246-61.

53. Hagiwara D, Asano Y, Marui J, Furukawa K, Kanamaru K, Kato M, Abe K, Kobayashi T, Yamashino T, Mizuno T. The SskA and SrrA response regulators are implicated in oxidative stress responses of hyphae and asexual spores in the phosphorelay signaling network of Aspergillus nidulans. Biosci Biotech Bioch. 2007;71(4):1003-14.

54. Fujioka T, Mizutani O, Furukawa K, Sato N, Yoshimi A, Yamagata Y, Nakajima T, Abe K. MpkA-dependent and -independent cell wall integrity signaling in Aspergillus nidulans. Eukaryot Cell. 2007;6(8):1497-510.

55. Etxebeste O, Ugalde U, Espeso EA. Adaptative and developmental responses to stress in Aspergillus nidulans. Curr Protein Pept Sci. 2010;11(8):704-18.

56. Gunde-Cimerman N, Ramos J, Plemenitaš A. Halotolerant and halophilic fungi. Mycol Res. 2009;113:1231-41.

57. Hagiwara D, Asano Y, Marui J, Yoshimi A, Mizuno T, Abe K. Transcriptional profiling for Aspergillus nidulans HogA MAPK signaling pathway in response to fludioxonil and osmotic stress. Fungal Genet Biol. 2009;46(11):868-78.

58. Miskei M, Karányi Z, Pócsi I. Annotation of stress-response proteins in the aspergilli. Fungal Genet Biol. 2009;46:S105-20.

59. Pollack JK, Harris SD, Marten MR. Autophagy in filamentous fungi. Fungal Genet Biol. 2009;46(1):1-8.

60. Cebollero E, Gonzalez R. Induction of autophagy by secondfermentation yeasts during elaboration of sparkling wines. Appl Environ Microbiol. 2006;72(6):4121-7.

61. Aguirre J, Ríos-Momberg M, Hewitt D, Hansberg W. Reactive oxygen species and development in microbial eukaryotes. Trends Microbiol. 2005;13(3):111-8.

62. Lockman PR, Allen DD. The transport of choline. Drug Dev Ind Pharm. 2002; 28(7):749-71.

63. Dowd SR, Bier ME, Patton-Vogt JL. Turnover of phosphatidylcholine in Saccharomyces cerevisiae - The role of the CDP-choline pathway. J Biol Chem. 2001;276(6):3756-63.

64. Gupta N, Balomajumder C, Agarwal VK. Enzymatic mechanism and biochemistry for cyanide degradation: a review. J Hazard Mater. 2010;176(1-3):1-13.

65. Chae HZ, Chung SJ, Rhee SG. Thioredoxin-dependent peroxide reductase from yeast. J Biol Chem. 1994;269(44):27670-8.

66. Khudyakov JI, D'haeseleer P, Borglin SE, DeAngelis KM, Woo H, Lindquist EA, Hazen TC, Simmons BA, Thelen MP. Global transcriptome response to ionic liquid by a tropical rain forest soil bacterium, Enterobacter lignolyticus. Proc Natl Acad Sci U S A. 2012;109(32):E2173-82

67. Zhang YQ, Brock M, Keller NP. Connection of propionyl-CoA metabolism to polyketide biosynthesis in Aspergillus nidulans. Genetics. 2004;168(2):785-94. 
68. Degenkolb T, Bruckner H. Peptaibiomics: towards a myriad of bioactive peptides containing C-alpha-dialkylaimino acids? Chem Biodivers. 2008;5(9):1817-43.

69. Degenkolb T, Kirschbaum J, Bruckner H. New sequences, constituents, and producers of peptaibiotics: an updated review. Chem Biodivers. 2007:4(6):1052-67

70. Walsh CT, Chen HW, Keating TA, Hubbard BK, Losey HC, Luo LS, Marshall CG, Miller DA, Patel HM. Tailoring enzymes that modify nonribosomal peptides during and after chain elongation on NRPS assembly lines. Curr Opin Chem Biol. 2001:5(5):525-34.

71. Litzka O, Papagiannopolous P, Davis MA, Hynes MJ, Brakhage AA. The penicillin regulator PENR1 of Aspergillus nidulans is a HAP-like transcriptional complex. Eur J Biochem. 1998;251(3):758-67.

72. Ahuja M, Chiang YM, Chang SL, Praseuth MB, Entwistle R, Sanchez JF, Lo HC, Yeh $\mathrm{HH}$, Oakley BR, Wang CC. Illuminating the diversity of aromatic polyketide synthases in Aspergillus nidulans. J Am Chem Soc. 2012;134(19):8212-21.

73. Soukup AA, Chiang YM, Bok JW, Reyes-Dominguez Y, Oakley BR, Wang CCC, Strauss J, Keller NP. Overexpression of the Aspergillus nidulans histone 4 acetyltransferase EsaA increases activation of secondary metabolite production. Mol Microbiol. 2012;86(2):314-30.

74. Nützmann HW, Reyes-Dominguez Y, Scherlach K, Schroeckh V, Horn F, Gacek A, Schümann J, Hertweck C, Strauss J, Brakhage AA. Bacteria-induced natural product formation in the fungus Aspergillus nidulans requires Saga/Ada-mediated histone acetylation. Proc Natl Acad Sci U S A. 2011;108(34):14282-7.

75. Bayram Ö, Krappmann S, Ni M, Bok JW, Helmstaedt K, Valerius O, BrausStromeyer S, Kwon NJ, Keller NP, Yu JH, et al. VelB/VeA/LaeA complex coordinates light signal with fungal development and secondary metabolism. Science. 2008;320(5882):1504-6.

76. Yu JH, Butchko RAE, Fernandes M, Keller NP, Leonard TJ, Adams TH. Conservation of structure and function of the aflatoxin regulatory gene aflR from Aspergillus nidulans and A. flavus. Curr Genet. 1996;29(6):549-55.

77. Yin W, Keller NP. Transcriptional regulatory elements in fungal secondary metabolism. J Microbiol. 2011;49(3):329-39.

78. Bok JW, Keller NP. LaeA, a regulator of secondary metabolism in Aspergillus spp. Eukaryot Cell. 2004;3(2):527-35

79. Calvo AM. The VeA regulatory system and its role in morphological and chemical development in fungi. Fungal Genet Biol. 2008:45(7):1053-61.

80. Bayram Ö, Braus GH. Coordination of secondary metabolism and development in fungi: the velvet family of regulatory proteins. FEMS Microbiol Rev. 2012;36(1):1-24.

81. Perrin RM, Fedorova ND, Bok JW, Cramer RAJ, Wortman JR, Kim HS, Nierman WC, Keller N. Transcriptional regulation of chemical diversity in Aspergillus fumigatus by LaeA. PLoS Pathog. 2007;3(4), e50.

82. Butchko RAE, Brown DW, Busman M, Tudzynski B, Wiemann P. Lae1 regulates expression of multiple secondary metabolite gene clusters in Fusarium verticillioides. Fungal Genet Biol. 2012;49(8):602-12.

83. Palmer JM, Keller NP. Secondary metabolism in fungi: does chromosomal location matter? Curr Opin Microbiol. 2010;13(4):431-6.

84. Shaaban MI, Bok JW, Lauer C, Keller NP. Suppressor mutagenesis identifies a velvet complex remediator of Aspergillus nidulans secondary metabolism. Eukaryot Cell. 2010;9(12):1816-24.

85. Ramamoorthy $V$, Dhingra S, Kincaid A, Shantappa S, Feng X, Calvo AM. The putative $\mathrm{C} 2 \mathrm{H} 2$ transcription factor MtfA is a novel regulator of secondary metabolism and morphogenesis in Aspergillus nidulans. PLoS ONE. 2013;8(9):e74122.

86. Shwab EK, Bok JW, Tribus M, Galehr J, Graessle S, Keller NP. Histone deacetylase activity regulates chemical diversity in Aspergillus. Eukaryot Cell. 2007;6(9):1656-64.

87. Reyes-Dominguez Y, Bok JW, Berger H, Shwab EK, Basheer A, Gallmetzer A, Scazzocchio C, Keller N, Strauss J. Heterochromatic marks are associated with the repression of secondary metabolism clusters in Aspergillus nidulans. Mol Microbiol. 2010;76(6):1376-86.

88. Chen L, Mullen GE, Le Roch M, Cassity CG, Gouault N, Fadamiro HY, Barletta RE, O'Brien RA, Sykora RE, Stenson AC. On the formation of a protic ionic liquid in nature. Angewandte Chemie (International ed in English). 2014;53(44):11762-5.

89. Eisendle M, Oberegger $\mathrm{H}$, Zadra I, Haas $\mathrm{H}$. The siderophore system is essential for viability of Aspergillus nidulans: functional analysis of two genes encoding L-ornithine $N^{5}$-monooxygenase (sidA) and a non-ribosomal peptide synthetase (sidC). Mol Microbiol. 2003:49(2):359-75.
90. Gründlinger M, Yasmin S, Lechner BE, Geley S, Schrettl M, Hynes M, Haas H. Fungal siderophore biosynthesis is partially localized in peroxisomes. Mol Microbiol. 2013;88(5):862-75.

91. Bromann K, Toivari M, Viljanen K, Vuoristo A, Ruohonen L, Nakari-Setälä T. Identification and characterization of a novel diterpene gene cluster in Aspergillus nidulans. PLoS ONE. 2012;7(4), e35450.

\section{Submit your next manuscript to BioMed Central and we will help you at every step:}

- We accept pre-submission inquiries

- Our selector tool helps you to find the most relevant journal

- We provide round the clock customer support

- Convenient online submission

- Thorough peer review

- Inclusion in PubMed and all major indexing services

- Maximum visibility for your research

Submit your manuscript at www.biomedcentral.com/submit
Biomed Central 